\title{
Design of Experiment Based Optimization of an in Vitro Direct Contact Triculture Blood Brain Barrier Model for Permeability Screening
}

\section{Kelsey E Lubin}

Purdue University College of Pharmacy

Gregory T. Knipp ( $\nabla$ gknipp@purdue.edu )

Department of Industrial and Physical Pharmacy, Purdue University, 575 Stadium Mall Drive, West Lafayette, Indiana 47907, USA. https://orcid.org/0000-0002-4199-2929

\section{Research}

Keywords: Blood brain barrier, permeability, design of experiments, optimization, astrocytes, pericytes, brain microvessel endothelium, triculture, direct cell-cell contact

Posted Date: June 10th, 2021

DOI: https://doi.org/10.21203/rs.3.rs-592200/v1

License: (a) (i) This work is licensed under a Creative Commons Attribution 4.0 International License. Read Full License 
$5 \quad$ Kelsey E. Lubin and Gregory T. Knipp*

* Corresponding author

Department of Industrial and Physical Pharmacy, Purdue University, 575 Stadium Mall Drive, West Lafayette, Indiana 47907, USA.

Running Title: DOE Optimization of a Direct Contact Triculture BBB Model

Submitted to: Fluids and Barriers of the CNS

* Corresponding author to whom correspondence should be addressed:

Gregory T. Knipp, Ph.D.

Industrial and Physical Pharmacy

College of Pharmacy

Purdue University

575 Stadium Mall Drive

West Lafayette, IN 47907-2091

Telephone: 765-494-3765

Fax: 765-494-6545

6 E-mail: gknipp@purdue.edu 
9 Background: The in vivo restrictive properties of the blood brain barrier (BBB) largely arise 10 from astrocyte and pericyte synergistic cell signaling interactions that underlie the brain 11 microvessel endothelial cells (BMEC). In vivo relevant direct contact between astrocytes, 12 pericytes, and BMECS, to our knowledge, has not been established in conventional Transwell ${ }^{\circledR}$ 13 based in vitro screening models of the BBB. We hypothesize that a design of experiments (DOE) 14 optimized direct contact layered triculture model will offer more in vivo relevance for screening 15 in comparison to indirect models.

16 Methods: Plating conditions including the seeding density of all three cell types, matrix protein, 17 and culture time were assessed in $\mathrm{DOE}_{\mathrm{P}}$. $\mathrm{DOE}_{\mathrm{P}}$ was followed by $\mathrm{DOE}_{\mathrm{M} 1}$ and $\mathrm{DOE}_{\mathrm{M} 2}$ to assess 18 the influence of medium additives on barrier properties. The permeability of $4 \mathrm{kD}$ dextran, a 19 paracellular marker, was the measured response to arrive at the optimal plating conditions. The 20 optimized model was further assessed for p-glycoprotein function using a substrate and inhibitor 21 along with a set of BBB paracellular and transcellular markers at varying permeation rates.

22 Results: $\mathrm{DOE}_{\mathrm{P}}$ revealed that length of culture post endothelial cell plating correlated highest 23 with paracellular tightness. In addition, seeding density of the endothelial cell layer influenced 24 paracellular tightness at earlier times of culture, and its impact decreased as culture is extended. 25 Medium additives had varying effects on barrier properties as seen from $\mathrm{DOE}_{\mathrm{M} 1}$ and $\mathrm{DOE} \mathrm{E}_{\mathrm{M} 2}$. At 26 optimal conditions, the model revealed P-gp function along with the ability to differentiate 27 between BBB positive and negative permeants.

28 Conclusions: We have demonstrated that the implementation of DOE based optimization for 29 biologically based systems is an expedited method to establish multi-component in vitro cell 
models. The direct contact $\mathrm{BBB}$ triculture model reveals that the physiologically relevant

31 layering of the three cell types is a practical method of culture to establish a screening model

32 compared to indirect plating methods that incorporate physical barriers between cell types.

33 Additionally, the ability of the model to differentiate between BBB positive and negative

34 permeants suggests that this model may be an enhanced screening tool for potential neuroactive 35 compounds.

Keywords: Blood brain barrier, permeability, design of experiments, optimization, astrocytes,

37 pericytes, brain microvessel endothelium, triculture, direct cell-cell contact

\section{$38 \quad$ Background}

There is a continuing need for screening models that will facilitate the development of therapeutic agents aimed at mitigating brain disorders, particularly as there is a rapidly increasing

41 prevalence of neurodegenerative and neurodevelopmental diseases.(1) The costs associated with

42 developing neurotherapeutics is significant in large part due to the high rates of attrition in later

43 stages of development.(2) The implementation of a low cost, predictive, and physiologically

44 relevant in vitro screening model to more rigorously facilitate hit to lead candidate selection

45 providing greater in vivo correlative rank ordering of potential compounds or drug delivery 46 systems for further development is imperative.

Many have theorized that the high rates of attrition are predominantly due to the inability

48 of drug candidates to cross the blood brain barrier (BBB).(1-3) The BBB has traditionally been

49 viewed as the brain microvessel endothelial cells (BMECs) that line the capillaries of the brain to 50 maintain a homeostatic environment. The BBB separates the brain parenchyma from the 51 systemic circulation and prevents permeation of potential xenobiotics into the brain interstitial 
52 fluids.(4,5) The BBB endothelium is unique in comparison to the periphery due to the high 53 expression of efflux proteins, drug transporters, metabolizing enzymes, and the presence of 54 restrictive tight junctions.(6,7) Tight junctions in the brain are formed between adjacent BMECs 55 by a complex of transmembrane intracellular cleft spanning proteins such as the occludins and 56 claudins 3 and 5, which anchor to cytosolic scaffolding proteins supported by the actin 57 cytoskeleton.(8-10) The presence of restrictive tight junctions limits the permeation of small 58 hydrophilic compounds, forcing compounds to move transcellularly in order to cross the BBB.

The high expression levels of non-substrate specific ATP-binding cassette (ABC) transporters such as P-glycoprotein (P-gp) and Breast Cancer Resistance Protein (BCRP) results

61 in a high degree of efflux for molecules that attempt to cross the BBB through the transcellular 62 pathway.(11) The presence of efflux transporters may limit the permeation of potential 63 neurotoxicants, while also presenting a challenge for drug delivery as a number of intended 64 neurotherapeutics tend to be lipophilic, favoring multidrug-resistant isoform efflux.(12) Due to 65 their unique presence in the $\mathrm{BBB}$, restrictive tight junctions and functional efflux proteins are 66 key validation characteristics when establishing an in vitro BBB screening model. The in vivo BBB phenotype is also largely modulated by the presence of supporting cellular and non-cellular components including astrocytes, pericytes, neurons, and the basal 69 lamina. Together, these components make up the neurovascular unit (NVU), which are each essential for the function of the BBB in vivo. Astrocytes are a glial cell type that fully surround 71 the endothelium and are linked to each other via gap junctions.(13) Single astrocytes have been 72 shown to interact with up to four different neurons and five blood vessels, making them the 73 cellular link between the endothelium and brain parenchyma.(14-16) Astrocytes participate in 74 ion and water regulation due to the localization of aquaporin 4 and ion channels in the astrocytic 
75 end-feet and have been linked to the secretion of basal lamina proteins.(10,17) Additionally,

76 astrocytes influence BMEC growth, modulation through extracellular signaling, play an

77 important metabolic role, and assist in the functional maintenance through the secretion of

78 soluble factors which have been shown to be essential for NVU homeostasis.(18-21) Towards

79 the latter point, several in vitro and in vivo studies have demonstrated that changes in BBB

80 integrity may result from a deficiency of certain astrocytic soluble factors.(18-21)

81 Pericytes are found enveloped in the basal lamina of the NVU between the astrocytes and

82 endothelium. However, pericyte distribution is not continuous and in general cover

83 approximately one third of the BMEC basal layer, with higher densities observed

84 regiospecifically within the brain.(22) Pericytes are believed to play a similar role as astrocytes

85 in NVU modulation through the secretion of soluble factors, but are unique in their role in NVU

86 formation and maintenance, specifically during development. $(23,24)$ Pericyte-endothelial

87 crosstalk occurs through a number of signal cascades including platelet-derived growth factor B

88 (PDGF-B) and transforming growth factor- $\beta$ (TGF- $\beta$ ), as well as others.(25) Interactions

89 between the pericytes and endothelium occurs within the basal lamina due to the relative location

90 of embedded pericytes in the shared basement membrane, potentially suggesting that the

91 composition of the extracellular matrix plays a role in BBB development and maintenance. The

92 basal lamina is a non-cellular component of the NVU and is responsible for maintaining integrity

93 of the BBB by anchoring the cellular components. There are a significant number of basement

94 membrane proteins that include fibronectin, collagen IV, laminins, and vitronectin that form the

95 matrix which is approximately $20 \mathrm{~nm}$ thick in vivo.(6,26,27) Given the multiple components that

96 make up the NVU, cellular and non-cellular, we propose that the BBB should be viewed as the 
97 directly interacting BMECs, pericytes and astrocytes of the NVU as a whole rather than simply 98 the contributions of the BMECs.

Since its establishment in 2005, the hTERT oncogene and SV40 immortalized human

100

101

102

103

104

105

106

107

108

109

110

111

112

113

114

115

116

117

118

119 cerebral microvessel endothelial cell line (hCMEC/D3) developed from primary endothelial cells of an epilepsy patient has been the most widely used immortalized endothelial cell line for BBB in vitro models. $(28,29)$ Although it is widely used, studies (as well as our observations, unpublished results) have revealed that hCMEC/D3 cells can have relatively "leaky" tight junctions and demonstrate a functional reduction in efflux transporter expression with passaging.(30-33) An alternative immortalized human brain endothelium is the HBEC-5i cell line that was singly transfected with SV40 and originates from a patient pool of cerebral cortex fragments, lacking pathological abnormalities.(34,35) The HBEC-5i has been used predominantly in the study of cerebral malaria; however, these studies have established the potential for this cell line to be used for BBB in vitro permeability screening.(35-38) These cells have been observed to express a high number of electron-dense tight junctions as seen under electron scanning microscopy, as well as provide high transendothelial electrical resistance (TEER) and low permeability comparable to other immortalized BMECs.(35) Recently, the HBEC-5i cell line has been used for in vitro modeling of the BBB showing functional expression of $\mathrm{ABC}$ transporters and stable barrier properties over multiple days of culture, suggesting they are a viable alternative to the hCMEC/D3 cell line and other immortalized BMEC sources. $(39,40)$

17 Given the interaction of multiple cell types that maintain the BBB phenotype in the NVU, many in vitro models include astrocytes and pericytes in conjunction with BMECs.(30,41-45) Typically, these models involve seeding the endothelium on the apical surface of the filter and 
120 the supporting astrocytes and pericytes in the basolateral chamber or on the reverse side of the

121 filter.(46-50) In this study we have further developed and optimized our previously established

122 direct contact, layered coculture model to form a triculture system with the inclusion of pericytes

123 to further increase the physiological relevance of the in vitro model.(51) The direct contact,

124 layered triculture model is cultured by seeding astrocytes, followed by pericytes, then the

125 endothelium all on the apical side of a filter support to reflect the in vivo configuration and cell-

126 cell contacts of the BBB in the in vivo NVU (Fig. 1). In our previous studies, we have utilized a

127 One Factor at a Time approach to optimize culturing variables in a laborious and time-

128 consuming manner. Given the multiple factors that influence the performance of this model, we

129 have now utilized a design of experiments (DOE) approach to determine optimal culturing

130 conditions by assessing the influence of multiple variables on barrier properties in a single

131 experiment. This study has demonstrated that a DOE based approach, typically utilized in non-

132 biological process optimization, can be used to optimize other multi-factor cell-based in vitro

133 systems by assessing variable influence on model performance. Additionally, the results of this

134 study demonstrate the importance of direct cell contact in in vitro models and suggests that

135 increasing physiological relevance of in vitro models to mimic the in vivo NVU BBB can further

136 enhance screening tools for neurotherapeutic development.

\section{Methods}

$138 \quad$ Materials

139 Transwell $^{\circledR}$ filters of $12 \mathrm{~mm} 0.4 \mu \mathrm{m}$ pore size, T-75 culture flasks, Matrigel ${ }^{\circledR}$, mouse 140 laminin, and type I rat tail collagen were purchased from Corning (Corning, NY, USA). Hank's 141 balanced salt solution (HBSS) and Dulbecco's Modified Eagle Medium/Nutrient Mixture F-12 142 (DMEM/F-12) were obtained from Gibco (Carlsbad, CA, USA). Fetal bovine serum (FBS), 
143 hydrocortisone, lithium chloride, retinoic acid, rhodamine 123 (R123), elacridar, digoxin, 144 carbamazepine, colchicine, clozapine, caffeine, and prazosin hydrochloride were purchased from 145 MilliporeSigma (St. Louis, MO, USA). HEPES (2-[4-(2-hydroxyethyl)piperazin-1-yl]146 ethanesulfonic acid) and calcium chloride dihydrate were obtained from J.T. Baker (Phillipsburg, 147 NJ, USA). Dexamethasone was obtained from MP Biomedicals (Santa Ana, CA, USA). 148 Endothelial cell growth supplement (ECGS) was purchased from Alfa Aesar (Haverhill, MA, 149 USA). Fluorescein isothiocyanate (FITC) labeled $4 \mathrm{kD}$ dextran was purchased from Chondrex 150 (Redmond, WA, USA). Poly-L-lysine (PLL) was purchased from Trevigen (Gaithersburg, MD, 151 USA). Radiolabeled compounds [14C]-mannitol, -sucrose, -inulin, -PEG-4000, and [3H]-L152 histidine were purchased from Moravek Biochemicals Inc. (Brea, CA, USA). Human astrocytes, 153 human brain vascular pericytes, astrocyte medium, pericyte medium, and astrocyte and pericyte 154 growth factors were all obtained from ScienCell Research Laboratories (Carlsbad CA, USA). 155 HBEC-5i cells were purchased from ATCC (Manassas, VA, USA).

156 Cell Culture

Human Brain Endothelial Cells (HBEC-5i) were maintained in T-75 culture flasks pre158 coated with Type I rat tail collagen with medium changes every 3 days and culturing at 80-90\% 159 confluency. The cells were utilized in the studies between passages 22 and 30. HBEC-5i culture 160 medium was made up of Dulbecco's Modified Eagle Medium/Nutrient Mixture F-12 (DMEM/F161 12) supplemented with $10 \% \mathrm{FBS}, 15 \mathrm{mM}$ HEPES, and $40 \mathrm{ug} / \mathrm{mL}$ endothelial cell growth 162 supplement (ECGS). Human astrocytes and human brain vascular pericytes are maintained in T16375 culture flasks pre-coated with poly-L-lysine with medium changes every 3 days and 164 subculturing at $80-90 \%$ confluency. For the studies presented herein, the astrocytes and pericytes 165 were utilized between passage 4 and 10. Astrocyte culture medium was made up of Astrocyte 
Medium supplemented with 5\% FBS, astrocyte growth supplement, and penicillin/streptomycin. Pericyte culture medium was made up of Pericyte Medium supplemented with 5\% FBS, pericyte growth supplement, and penicillin/streptomycin.

\section{Experimental Design for Optimization}

Optimization of plating conditions (cell seeding densities, extracellular matrix protein, and length of culture) and medium additives were performed in sequential design of experiment (DOE) analyses. For plating studies $\mathrm{JMP}^{\circledR} 13.2$ from SAS statistical software was used to determine the plating conditions of each experimental run for a total of 39 combinations by utilizing a 5 factor, 2 level, custom design $\left(\mathrm{DOE}_{\mathrm{P}}\right)$. Each run was done in a single replicate with $\mathrm{DOE}_{\mathrm{P}}$ selected conditions to determine best levels for each variable and then the combined optimized conditions were further confirmed in subsequent experiments in triplicate. Table 1 lists the various factors and the respective levels of each.

Table 1. Plating factors and conditions for DOE $\left(\mathrm{DOE}_{\mathrm{P}}\right)$

\begin{tabular}{lc}
\hline Factor & Selected Range* \\
\hline Astrocyte Seeding Density & $20,000-60,000$ cells $/ \mathrm{cm}^{2}$ \\
Pericyte Seeding Density & $20,000-60,000$ cells $/ \mathrm{cm}^{2}$ \\
HBEC-5i Seeding Density & $50,000-110,000$ cells $/ \mathrm{cm}^{2}$ \\
Study Day & Day $5-9$ \\
Extracellular Matrix & Collagen I, Matrigel, Laminin \\
\hline 3 levels each factor &
\end{tabular}

Similarly, medium optimization was performed in two analyses using a custom design DOE to determine medium conditions that resulted in the tightest barrier properties. The first analysis (DOE $\left.\mathrm{D}_{\mathrm{M}}\right)$ was performed using HEPES, hydrocortisone, dexamethasone, LiCl, calcium, and retinoic acid, using the selected date for permeability analysis at 9 days post endothelial cell plating (Table 2). A second analysis $\left(\mathrm{DOE}_{\mathrm{M} 2}\right)$ was performed, based on the results of the first, 
using hydrocortisone, dexamethasone, $\mathrm{LiCl}$, and retinoic acid at both 5 and 7 days post endothelial cell plating (Table 3).

Table 2. Medium optimization with evaluation on Day 9 (DOE $\left.\mathrm{D}_{1}\right)$

\begin{tabular}{lc}
\hline Factor & Selected Range* \\
\hline HEPES & $15-25 \mathrm{mM}$ \\
Hydrocortisone & $0-1.4 \mu \mathrm{M}$ \\
Dexamethasone & $0-10 \mu \mathrm{M}$ \\
Lithium Chloride & $0-10 \mathrm{mM}$ \\
Calcium & $0-1 \mathrm{mM}$ \\
Retinoic Acid & $0-10 \mu \mathrm{M}$ \\
Study Day & Day 9 \\
\hline
\end{tabular}

* 2 levels each factor (presence or absence of given additive)

Table 3. Medium optimization with evaluation on Day 5 and $7\left(\mathrm{DOE}_{\mathrm{M} 2}\right)$

\begin{tabular}{lc}
\hline Factor $^{+}$ & Selected Range* \\
\hline Hydrocortisone & $0-1.4 \mu \mathrm{M}$ \\
Dexamethasone & $0-10 \mu \mathrm{M}$ \\
Lithium Chloride & $0-10 \mathrm{mM}$ \\
Retinoic Acid & $0-10 \mu \mathrm{M}$ \\
Study Day & Day 5 or 7 \\
\hline${ }^{+}$All medium supplemented with $15 \mathrm{mM}$ HEPES \\
$* 2$ levels each factor (presence or absence of given additive)
\end{tabular}

\section{Plating Direct Contact Triculture on Transwell ${ }^{\circledR}$ Filter Support}

For the DOEP studies, filters were pre-coated with poly-L-lysine (PLL) by pre-coating 12 $\mathrm{mm}, 0.4 \mu \mathrm{m}$ pore Transwell ${ }^{\circledR}$ inserts with $5 \mu \mathrm{g} / \mathrm{cm}^{2}$ PLL. Astrocytes were plated at seeding densities of $20,000,40,000$, or 60,000 cells $/ \mathrm{cm}^{2}$ and allowed to grow for 48 hours. After 48 hours of astrocyte growth, astrocyte medium was removed and pericytes were seeded atop the astrocyte lawn at seeding densities of $20,000,40,000$, or 60,000 cells $/ \mathrm{cm}^{2}$ and allowed to grow for 48 hours. After 48 hours of pericyte growth, apical medium was replaced with the specified ECM protein solution. Astrocyte-pericyte lawn filters were coated with one of the following ECM proteins at the respective concentrations: Matrigel ${ }^{\circledR} 25 \mu \mathrm{L} / \mathrm{cm}^{2}\left(2.5 \mu \mathrm{g} / \mathrm{cm}^{2}\right)$, Laminin $5 \mu \mathrm{g} / \mathrm{cm}^{2}$, 
208 or Type I Rat Tail Collagen $5 \mu \mathrm{g} / \mathrm{cm}^{2}$. To coat inserts, Matrigel ${ }^{\circledR}$, Laminin, or collagen I aliquots were diluted in HBSS with $\mathrm{Ca}^{2+}$ and $\mathrm{Mg}^{2+}$ and $0.5 \mathrm{~mL}$ dispensed onto to each respective $12 \mathrm{~mm}$ 210 insert and left to incubate with the respective ECM protein for 45 min at $37^{\circ} \mathrm{C}$. After incubation, 211 the ECM solution was removed and HBEC-5i cells were plated at seeding densities of 50,000, 21280,000 , or 110,000 cells $/ \mathrm{cm}^{2}$ and allowed to grow for 5,7 , or 9 days prior to permeability 213 measurements. Cultures were maintained in complete HBEC-5i medium with medium changes 214 every other day following endothelial cell plating. Transendothelial electrical resistance (TEER) 215 was measured every 24 hours after HBEC-5i plating using a $4 \mathrm{~mm}$ Chopstick electrode with 216 EVOM2 Volt/Ohm Meter (World Preclinical Instruments), and normalized based on resistance 217 across blank filter supports.

218 In DOE $\mathrm{M}_{1 / 2}$ studies, the culturing methodology described above was used with the 219 modification that the complete HBEC-5i culture medium was supplemented with the DOE 220 selected factors and introduced to cultures 24 hours post endothelial plating with medium 221 changes every other day until the day of study. Medium for DOE $\mathrm{M}_{1 / 2}$ was prepared from 222 concentrated stock solutions of 1 M HEPES in water, 4.6 mM hydrocortisone in ethanol, $3.8 \mathrm{mM}$ 223 dexamethasone in $\mathrm{DMSO}, 11.8 \mathrm{M} \mathrm{LiCl}$ in water, $1.7 \mathrm{M} \mathrm{CaCl}_{2}$ in water, and $33.3 \mathrm{mM}$ retinoic 224 acid in DMSO. Final solvent content was normalized across all runs to eliminate solvent effect as 225 a confounding factor in the study.

\section{Plating Monoculture and Direct Contact Coculture on Transwell ${ }^{\circledR}$ Filter Support}

228 pericyte-HBEC-5i) models were used for comparison with the DOE optimized direct contact 229 triculture. For monoculture studies, $12 \mathrm{~mm}, 0.4 \mu \mathrm{m}$ pore Transwell ${ }^{\circledR}$ inserts were pre-coated with $23025 \mu \mathrm{L} / \mathrm{cm}^{2}$ Matrigel $^{\circledR}$. HBEC-5i cells were plated on Matrigel ${ }^{\circledR}$ coated filters at a density of 
23180,000 cells $/ \mathrm{cm}^{2}$ and cultured for 9 days with medium changed every other day. Direct contact 232 cocultures were plated according to methods developed by Kulczar et al. with some 233 modifications.(51) Transwell ${ }^{\circledR}$ filters were pre-coated with $5 \mu \mathrm{g} / \mathrm{cm}^{2}$ PLL followed by seeding of 234 astrocytes or pericytes at 20,000 cells $/ \mathrm{cm}^{2}$ and allowed to grow for 48 hours. At 48 hours post 235 astrocyte or pericyte plating, HBEC-5i cells at 80,000 cells $/ \mathrm{cm}^{2}$ were seeded directly atop the 236 lawn of pre-seeded cells and cultured for an additional 9 days with medium changed every other 237 day.

\section{Permeability Assays}

To optimize conditions, permeability was measured using $4 \mathrm{kD}$ FITC-dextran at an initial concentration of $0.25 \mathrm{mg} / \mathrm{mL}$ in $\mathrm{HBSS}$ with $\mathrm{Ca}^{2+}$ and $\mathrm{Mg}^{2+}$. Triculture DOE generated plating conditions and the optimized parameters were washed and left to equilibrate in HBSS at $37{ }^{\circ} \mathrm{C}$

242 for 30 minutes prior to the start of the permeability assay. Permeability was performed at $37{ }^{\circ} \mathrm{C}$ 243 on a rocking platform maintaining sink conditions and sampling at 15, 30, 45, 60, and 90 244 minutes. Samples of $100 \mu \mathrm{L}$ from each basolateral chamber were removed at each time point and 245 placed into a 96-well black flat-bottomed well plate for fluorescence reading. After sampling, naïve HBSS was added back to the basolateral chamber to maintain hydrostatic pressure and the 247 lost mass was accounted for in the calculated permeation rates. Samples were analyzed using a 248 BioTek Synergy 4 plate reader at excitation of $485 \mathrm{~nm}$ and emission of $530 \mathrm{~nm}$. Apparent permeability $\left(\mathrm{P}_{\mathrm{app}}\right)$ was calculated using equation 1 (eq. 1)

252 where $\mathrm{dM} / \mathrm{dT}$ is the amount of Dextran that moves across the filter over time, Co is the initial 253 concentration in the donor (apical) chamber, and A is the surface area of the filter support. The 
254 effective permeability ( $\mathrm{P}_{\text {eff, }}$, permeability contributions of cell layer alone) of each condition was

255 determined using equation 2 (eq. 2) where the $\mathrm{P}_{\text {filter }}$ value used is that of the ECM used in the 256 given condition.

$$
\frac{1}{P_{\text {app }}}=\frac{1}{P_{\text {eff }}}+\frac{1}{P_{\text {filter }}}
$$

Apparent permeability of additional paracellular markers of varying sizes $\left(\left[{ }^{14} \mathrm{C}\right]-\right.$ mannitol, $\left[{ }^{14} \mathrm{C}\right]$-sucrose, $\left[{ }^{14} \mathrm{C}\right]$-inulin, and $\left[{ }^{14} \mathrm{C}\right]$-PEG-4000) was determined in the optimized 262 direct contact triculture. Permeability assays were performed as stated above with an initial concentration of $0.25 \mu \mathrm{Ci} / \mathrm{mL}$ in HBSS for all markers and analysis performed utizing a liquid 264 scintillation counter. properties of the optimized model. The permeability of $\left[{ }^{3} \mathrm{H}\right]$-L-histidine, carbamazepine, 267 colchicine, digoxin, clozapine, and prazosin was determined by preparing $10 \mathrm{mM}$ stock solutions 268 of each compound in DMSO, with the exception of $\left[{ }^{3} \mathrm{H}\right]$-L-histidine. For each study, the final 269 concentration of DMSO was equivalent at $1 \%(\mathrm{v} / \mathrm{v})$. Permeability of $\left[{ }^{3} \mathrm{H}\right]$-L-histidine was 270 determined using the same method as stated above for radiolabeled paracellular markers. 271 Working solutions of non-radiolabeled compounds were prepared at a concentration of $25 \mu \mathrm{M}$ in 272 HBSS with permeability measurements performed as stated above and sampling at 30, 60, 90, 273120 , and 150 minutes. Analysis for these compounds was performed using high performance 274 liquid chromatography (HPLC). Permeability was calculated according to equation 1. 
$277 \mathrm{R} 123(2 \mathrm{mM})$ and elacridar $(10 \mathrm{mM})$ were prepared in DMSO. Working solutions of $10 \mu \mathrm{M}$

$278 \mathrm{R} 123$ and $2 \mu \mathrm{M}$ elacridar were prepared in HBSS with 1\% DMSO. For inhibition studies,

279 tricultures plated on permeable filter supports were pre-incubated with $2 \mu \mathrm{M}$ elacridar for 45

280 minutes prior to the addition of R123. Samples were removed at 30, 60, 90, and 120 minutes and

281 analysis was performed using the BioTek Synergy 4 plate reader at excitation of $485 \mathrm{~nm}$ and

282 emission of $530 \mathrm{~nm}$. Permeability was calculated according to equation 1.

\section{High Performance Liquid Chromatography}

Analysis of carbamazepine, caffeine, colchicine, digoxin, clozapine, and prazosin was

performed on an Agilent 1100 reverse phase HPLC with variable wavelength detection (VWD),

as briefly described below and summarized in Table 4.

287 Table 4. High Performance Liquid Chromatography analyses performed on an Agilent 1100 288 reverse phase HPLC with variable wavelength detection (VWD).

\begin{tabular}{lcccc}
\hline Compound & $\begin{array}{c}\text { Column } \\
\text { temperature }\end{array}$ & $\begin{array}{c}\text { Mobile phase } \\
\text { (water:acetonitrile) }\end{array}$ & $\begin{array}{c}\text { Flow rate } \\
(\mathrm{mL} / \mathrm{min})\end{array}$ & $\begin{array}{c}\text { Absorbance } \\
\text { measurement (nm) }\end{array}$ \\
\hline Caffeine & ambient & $90: 10$ & 1.0 & 275 \\
Carbamazepine & $40{ }^{\circ} \mathrm{C}$ & $65: 35$ & 1.5 & 284 \\
Clozapine & $40{ }^{\circ} \mathrm{C}$ & $45: 55$ & 1.5 & 254 \\
Colchicine & $40{ }^{\circ} \mathrm{C}$ & $75: 25$ & 1.5 & 354 \\
Digoxin & $40{ }^{\circ} \mathrm{C}$ & $70: 30$ & 1.1 & 218 \\
Prazosin & $40{ }^{\circ} \mathrm{C}$ & $65: 35$ & 1.5 & 254 \\
\hline
\end{tabular}

All samples were run isochratically through an Ascentis ${ }^{\circledR} \mathrm{C}-1815 \times 4.6 \mathrm{~mm}, 5 \mu \mathrm{m}$ column, at $25 \mu \mathrm{L}$ injection volume, using water and acetonitrile (ACN) for all mobile phase.

\section{Statistical Analysis}

Custom experimental designs based on categorical and discrete continuous factors were generated by JMP 13.2 statistical software. Analysis of each DOE was done by fitting models based on the $\mathrm{P}_{\text {eff }}$ of $4 \mathrm{kD}$ dextran response to standard least squares to determine optimal conditions. In comparison studies, all conditions were performed in triplicate $(n=3)$ and subjected considered to be statistically significant. 


\section{Results}

297 Plating Optimization (DOE $)$

Traditionally, a One-Factor-at-a-Time (OFAT) approach is used to assess the impact of

299 variable changes in cell-based models and processes, where one variable (e.g., cell density) is optimized in the presence of several other unoptimized variables that results in an inefficient and laborious manner. A Design of Experiments (DOE) based approach allows for the influence of multiple factors to be observed on a measured response to arrive at an optimal level for each given variable. Furthermore, it allows one to more rapidly identify optimized growth conditions

304 in a time and labor efficient manner. Our previous studies towards establishing a direct contact triculture (unpublished results) and our direct contact coculture model, were used to inform our selection of respective seeding densities for all three cell types, ECM used to aid endothelial attachment, and length of culture of the endothelium that consisted of the initial selected factor ranges.(51) Optimal plating conditions were determined using $\mathrm{P}_{\text {eff }}$ values to account for the 309 differences associated with ECM coatings. Conditions 8 (60 HA, 60 HBVP, 110 EC, Laminin, Day 9) and 20 (20 HA, 20 HBVP, 110 EC, Laminin, Day 9) exhibited the lowest Peff values at $3.2 \times 10^{-6} \mathrm{~cm} / \mathrm{sec}$ (Fig. 2). Condition details and tabulated $\mathrm{P}_{\mathrm{eff}}$ data of DOEP are noted in Additional File 1.

Based on the data trends, the culture length between the assay day was determined to 314 have the largest impact on paracellular permeability resulting in significantly lower $4 \mathrm{kD}$ dextran 315 permeability at day 9 compared to days 5 and 7 . When separating the data by study day and 316 factor there are observable trends in permeability coefficients among the factors including the 317 effects of astrocyte and pericyte cell density. With extended culturing, higher seeding densities 318 of astrocytes and pericytes result in higher permeability of the dextran (Fig. 3). HBEC-5i seeding 
319 density also shows trends towards lower permeability at higher seeding densities; however, this

320 trend is not as strong at day 9 when the cells have had sufficient time to reach confluence and

321 have a longer time to differentiate.

322 Using JMP 13.2 software, a prediction profiler was generated based on the obtained $\mathrm{P}_{\mathrm{eff}}$

323 values for the given conditions. By maximizing Desirability to achieve the lowest possible

324 permeability, the optimal conditions were determined to be 20,000 cells $/ \mathrm{cm}^{2}$ for both astrocytes

325 and pericytes, 80,000 cells/cm ${ }^{2}$ HBEC-5i cells, Matrigel ${ }^{\circledR}$ as the ECM protein, and culturing for

3269 days post endothelial cell plating (Fig. 4). These conditions would optimally generate a

327 predicted $\mathrm{P}_{\mathrm{eff}}$ value of $2.4 \times 10^{-6} \mathrm{~cm} / \mathrm{sec}$ for $4 \mathrm{kD}$ dextran. Upon repeating the analysis at selected

328 optimal conditions, the $\mathrm{P}_{\text {eff }}$ of a $4 \mathrm{kD}$ dextran showed to be reproducible resulting in a similar

329 permeability value $\left(\mathrm{P}_{\mathrm{eff}} ; 3.7 \times 10^{-6} \mathrm{~cm} / \mathrm{sec} \pm 0.04, \mathrm{n}=3\right)$.

330

331

332

333

334

335

336

337

338

339

340

341

\section{Medium Optimization ( $\left.\mathrm{DOE}_{\mathrm{M} 1 / 2}\right)$}

Selection of medium additives was based on literature and previous studies in our laboratory for HBEC-5i medium based on their reported influences on barrier tightness both in vitro and in vivo.(51-58) The first DOE analysis of medium variables aimed towards optimization $\left(\mathrm{DOE}_{\mathrm{M} 1}\right)$ was performed with the DOE optimized plating conditions of 20,000 cells $/ \mathrm{cm}^{2}$ for astrocytes and pericytes, 80,000 cells/ $\mathrm{cm}^{2}$ HBEC-5i, Matrigel, after 9 days of endothelial growth. HEPES, hydrocortisone, dexamethasone, lithium chloride, calcium, and retinoic acid were used as medium additives due their reported influence on tight junction expression and induction of barrier properties in in vitro $\mathrm{BBB}$ models. The lowest achieved $4 \mathrm{kD}$ dextran $\mathrm{P}_{\text {eff }}$ of $\mathrm{DOE}_{\mathrm{M} 1}$ was $6.3 \times 10^{-6} \mathrm{~cm} / \mathrm{sec}$, suggesting that, under these conditions, the additives did not provide further tightening of the model. Significant trends are not apparent for any of the additives with the exception of higher levels of HEPES resulting in higher 
342 permeability values. Given that many of these additives increased expression and differentiation

343 of the endothelial cells, their effects on barrier properties were assessed at earlier days of culture.

344 The optimal medium condition was determined to be $15 \mathrm{mM}$ HEPES, $1 \mathrm{mM}$ calcium, and $10 \mu \mathrm{M}$

345 retinoic acid, but the influence of these factors on barrier tightness was not significant (Fig. 5).

346 The full data set of $\mathrm{DOE}_{\mathrm{M} 1}$, including medium conditions and $\mathrm{P}_{\text {eff }}$, is tabled in Additional File 2.

347 Based on these results a second analysis $\left(\mathrm{DOE}_{\mathrm{M} 2}\right)$ was performed to assess the influence

348 of the additives in earlier days of culture. These studies were conducted in the presence or

349 absence of hydrocortisone, dexamethasone, lithium chloride, and retinoic acid at 5 and 7 days

350 post endothelial cell culture, HEPES was held constant at $15 \mathrm{mM}$ and calcium was removed from

$351 \mathrm{DOE}_{\mathrm{M} 2}$. The lowest $4 \mathrm{kD}$ dextran $\mathrm{P}_{\mathrm{eff}}$ of $\mathrm{DOE}_{\mathrm{M} 2}$ was $8.3 \times 10^{-6} \mathrm{~cm} / \mathrm{sec}$, suggesting that the

352 additives do not provide increased barrier tightness based on the optimized plating conditions of

353 DOE . Optimal conditions for medium was determined to be $10 \mu \mathrm{M}$ dexamethasone, $10 \mu \mathrm{M}$

354 retinoic acid, $10 \mathrm{mM} \mathrm{LiCl}$, through 7 days of endothelial cell culture; however, these conditions

355 were not used for continued assessment of the optimized model due to the lack of improvement

356 over unmodified medium (Fig. 6). The complete data set of $\mathrm{DOE}_{\mathrm{M} 2}$, including individual run and

$357 \quad \mathrm{P}_{\text {eff }}$ results, can be found in Additional File 3.

\section{Permeation Comparisons to Mono- and Cocultures}

359 The optimized direct contact triculture was compared to a monoculture of HBEC-5i cells

360 alone and direct contact cocultures of HEBC-5i cells seeded atop a lawn of astrocytes or

361 pericytes (Fig. 7A). Effective permeability of the $4 \mathrm{kD}$ FITC-dextran was used for comparison

362 between the different models. In comparison to the optimized direct contact triculture $\left(3.7 \times 10^{-6}\right.$

$363 \pm 0.0 \mathrm{~cm} / \mathrm{sec})$ the HBEC-5i monoculture had the highest observed permeability $\left(19.7 \times 10^{-6} \pm 3.0\right.$

$364 \mathrm{~cm} / \mathrm{sec} ; \mathrm{p}<0.01)$, followed by the perictye-HBEC-5i coculture $\left(15.1 \times 10^{-6} \pm 3.7 \mathrm{~cm} / \mathrm{sec} ; \mathrm{p}<\right.$ 
365 366

367 368

$0.05)$, and the astrocyte-HBEC-5i coculture $\left(12.8 \times 10^{-6} \pm 2.1 \mathrm{~cm} / \mathrm{sec} ; \mathrm{p}<0.05\right)$. Given the significant differences observed between the direct contact triculture and the monoculture and coculture models, the inclusion of all three cell types offers increased barrier tightness for the in vitro model.

\section{Direct Contact Triculture BBB Marker Compounds}

Paracellular markers possessing a broad range of hydrodynamic radii were used to evaluate the functional tightness of the optimized model (Fig. 7B).(59-61) The lowest apparent paracellular permeability observed was that of PEG-4000 $\left(7.85 \times 10^{-6} \pm 0.03 \mathrm{~cm} / \mathrm{sec}, 15.9 \AA\right)$ followed by inulin $\left(\mathrm{P}_{\mathrm{app}}=15.53 \times 10^{-6} \pm 0.15 \mathrm{~cm} / \mathrm{sec}, 10 \AA\right)$, mannitol $\left(\mathrm{P}_{\mathrm{app}}=19.88 \times 10^{-6} \pm 0.07\right.$ $\mathrm{cm} / \mathrm{sec}, 4.3 \AA$ ) , and sucrose $\left(\mathrm{P}_{\text {app }}=21.76 \times 10^{-6} \pm 0.17 \mathrm{~cm} / \mathrm{sec}, 5.2 \AA\right)$. The apparent paracellular permeability of the hydrophilic markers shows the model is able to distinguish between markers of varying sizes. However, based on the hydrodynamic radius, sucrose should have a lower permeability as the larger compound in comparison to mannitol.

P-gp function in the direct contact triculture was assessed using P-gp substrate R123 alone and in the presence of P-gp inhibitor elacridar (Fig. 7C). In the absence of inhibitor, the $\mathrm{P}_{\text {app }}$ of R123 was $18.52 \times 10^{-6} \pm 0.58 \mathrm{~cm} / \mathrm{sec}$. The presence of elacridar significantly increased the $\mathrm{P}_{\mathrm{app}}$ of $\mathrm{R} 123\left(\mathrm{P}_{\mathrm{app}}=21.14 \times 10^{-6} \pm 0.46 \mathrm{~cm} / \mathrm{sec} ; \mathrm{p}<0.01\right)$ across the direct contact triculture. Additional P-gp substrates were utilized as marker compounds such as digoxin $\left(\mathrm{P}_{\mathrm{app}}=9.21 \times 10^{-}\right.$ $\left.{ }^{6} \pm 0.31 \mathrm{~cm} / \mathrm{sec}\right)$ and colchicine $\left(\mathrm{P}_{\mathrm{app}}=18.67 \times 10^{-6} \pm 2.75 \mathrm{~cm} / \mathrm{sec}\right)$. Prazosin, a BCRP substrate, was used to assess the function of other efflux transporters in the direct contact model $\left(\mathrm{P}_{\text {app }}=\right.$ $\left.6.16 \times 10^{-6} \pm 0.11 \mathrm{~cm} / \mathrm{sec}\right)($ Fig. 8$)$.

The antipsychotic drug clozapine showed an apparent permeability value of $8.15 \times 10^{-6} \pm$ $0.58 \mathrm{~cm} / \mathrm{sec}$. The amino acid L-histidine was used to assess facilitative transport across the in 
vitro model with an observed apparent permeability of $52.61 \times 10^{-6} \pm 0.70 \mathrm{~cm} / \mathrm{sec}$, as reported previously.(60) Carbamazepine is an antiepileptic drug and a BBB positive permeant with an observed apparent permeability of $27.71 \times 10^{-6} \pm 1.13 \mathrm{~cm} / \mathrm{sec}$ in the optimized model. Caffeine, a small hydrophilic molecule, also had BBB positive permeation with an obtained apparent permeability of $28.93 \times 10^{-6} \pm 1.15 \mathrm{~cm} / \mathrm{sec}$ (Fig. 8).

\section{Discussion}

In vitro screening models have traditionally been used to evaluate the potential of new chemical entities to cross the $\mathrm{BBB}$, with much of the emphasis of these models being placed on the endothelial cell type. The BMEC used is often primary or immortalized and of animal or human origin, each presenting its own advantages for use in in vitro models. $(30,62)$ Although animal sources are typically lower cost, have significantly higher access, and can be easier to isolate, physiological and phenotypic differences between the human and animal NVU make human cell sources preferred for drug permeability screening due to the presumed physiological relevance to the patient. Primary cells, directly isolated from patients, often present a phenotype most similar to in vivo, but are often difficult to acquire due to ethical reasons, require intricate isolation protocols, and present concerns with patient specific differences. $(63,64)$ Therefore, much of the emphasis has been placed on establishing and characterizing human immortalized cell lines for robust screening methods.

The HBEC-5i cell line has not been as extensively used for in vitro BBB permeability modeling comparative to other BMEC cell sources (e.g., hCMEC/D3).(60) However, it has been shown to have good expression levels of brain endothelial markers such as vascular cell adhesion molecule (VCAM-1) and intercellular adhesion molecule (ICAM-1) essential for immune cell trafficking, CD51 ( $\alpha_{\mathrm{v}}$-integrin) involved in extracellular matrix adhesion, as well as tight 
411 junction proteins zonula occluden 1 (ZO-1) and claudin-5.(35,39) Transporter expression and

412 function of BCRP, P-gp, MRP-1, and MRP-2 has also been demonstrated recently to be

413 comparable to other immortalized brain endothelium.(39) Conversely, this cell line has also been

414 indicated to be lacking in expression of platelet endothelial cell adhesion molecules (PECAM-1

415 and CD31) and the macrophage scavenger receptor CD36.(35,65) Given the expression of

416 endothelial markers and transporters that have been investigated by others, we selected the

417 HBEC-5i cell line as the BMEC for the direct contact triculture rather than the hCMEC/D3 cell

418 line we utilized in development of the direct contact coculture.(51)

In vitro models of the $\mathrm{BBB}$ are increasingly being developed to provide physiological

420 relevance through co- and triculture indirect contact methods with astrocytes and pericytes that

421 comprise the NVU to further enhance barrier properties. Seeding supporting NVU cells on the

422 reverse side of the filter support displays improved barrier properties in the cultured BMECs by

423 reducing the distance between the cell types and improving the BBB phenotype in the cultured

424 endothelium. $(50,66)$ However, the direct cell-cell contact is limited due to the thickness of the

425 filter support and opposable culturing surfaces, where growth through the filter pores provides

426 limited interaction. The direct cell-cell contacts of astrocytes and pericytes with the endothelium

427 in vivo are often overlooked in these multi-cellular models that are currently utilized. $(30,41-45)$

428 We have previously shown that direct contact between astrocytes and the endothelium in a 429 coculture model increases the barrier properties compared to endothelial monocultures and 430 indirect plating methods.(51) Although astrocytes are often used as a supporting cell in in vitro 431 models, pericytes also play an important role in influencing and regulating the BBB phenotype 432 through a number of signaling cascades.(24,67,68) Since each supporting cell acts in a 433 functionally different manner on the BMECs, incorporating both astrocytes and pericytes in 
434

435

436

437

438

439

440

441

442

443

444

445

446

447

448

449

450

451

452

453

454

455

direct contact cell based models should better enable synergistic effects of the NVU to be represented in vitro.

A design of experiments approach was taken to develop and optimize the direct contact triculture in order to adequately understand the interactions each variable would have on the performance of the model. As opposed to an OFAT approach, DOE takes into account the implications of changing multiple variables to come to optimal conditions in a significantly more efficient manner in terms of time invested and resources required. In optimizing the triculture, we arrived at optimal conditions with reproducible results in a time frame of two months as opposed to our previous OFAT optimization efforts that spanned the course of multiple years. The results of DOEP revealed optimal plating conditions of 20,000 cells $/ \mathrm{cm}^{2}$ for both astrocytes and pericytes, 80,000 cells $/ \mathrm{cm}^{2}$ for HBEC-5i, Matrigel ${ }^{\circledR}$ as the ECM to promote endothelial adhesion, and culturing the endothelium for 9 days after seeding. The comparison of $4 \mathrm{kD}$ dextran permeability to other reported data revealed that our optimized model infers that the model is among the tightest we found reported, suggesting that culturing multiple NVU cell types in direct contact synergistically increases barrier tightness (Table 5).

Table 5. Peff Values of 4 kD Dextran (14 A) for different BBB models.

\begin{tabular}{|c|c|}
\hline Model/Endothelial Cell Line & Peff $\left(10^{-6} \mathrm{~cm} / \mathrm{sec}\right)$ \\
\hline DOE Direct Contact Triculture, HBEC-5i & 3.7 \\
\hline Monoculture (HA conditioned medium), HBEC-5i & $3.6^{\mathrm{a}}$ \\
\hline Monoculture, hCMEC/D3 & $8.8^{\mathrm{b}}, 5.4^{\mathrm{c}}$ \\
\hline Isolated endothelial cells, rat & $1.0^{\mathrm{d}}$ \\
\hline In vivo microvessels, rat & $0.92^{\mathrm{e}}$ \\
\hline
\end{tabular}


In addition to selecting an optimized set of plating conditions, the DOE approach

457 facilitated an understanding of how changing factor levels may impact model performance. At

458 higher densities of astrocytes and pericytes, a decrease in paracellular tightness was observed

459 with extended culture time. Length of culturing time will vary with each individual endothelial

460 cell line seeded in combination with the astrocytes and pericytes in culture and should be

461 optimized based on the increase in tightness as an indicator of differentiation. However, the

462 endothelial culture times do need to take into account whether or not the co-cultured astrocytes

463 and pericytes maintain viability or run the risk of becoming senescent at the latter stages of the

464 study. Additionally, higher seeding densities of endothelial cells resulted in lower paracellular

465 permeation rates at days 5 and 7, which may be expected by the increased ability of the cells to

466 form a confluent layer at fewer days of culture. However, that trend is less drastic after 9 days of

467 culture suggesting that seeding density does not play as significant of a role at confluency, but

468 rather time in culture is necessary to allow for differentiation and adequate tight junction 469 formation.

An effort to optimize culture medium $\left(\mathrm{DOE}_{\mathrm{M} 1}\right.$ and $\left.\mathrm{DOE}_{\mathrm{M} 2}\right)$ was made to further increase

471 barrier properties of the model through the inclusion of additives that have been shown to

472 enhance the BBB phenotype in in vitro and in vivo studies. Unmodified HBEC-5i medium

473 contains $15 \mathrm{mM}$ HEPES; therefore, higher levels of HEPES were included to assess the impact

474 of a higher buffering capacity on barrier tightness. Hydrocortisone was selected for its influence

475 on inflammatory responses as a glucocorticoid and potential to prevent tight junction break 476 down.(52) Lithium chloride has been shown to influence claudin expression through stimulation

477 of the Wnt/ $\beta$-catenin pathway.(53) Calcium was studied as a medium additive due to its

478 influence on adherens and tight junction protein expression to increase barrier tightness, where 
479 studies have shown that low extracellular calcium levels can lead to an increase in paracellular 480 permeability.(54,55) Like hydrocortisone, dexamethasone acts to inhibit inflammatory responses 481 and upregulate tight junctions; however, it is a synthetic alternative to the naturally occurring 482 hydrocortisone.(56) Lastly, retinoic acid is naturally secreted by glial cells and has revealed 483 significant increases in paracellular tightness in in vitro BBB models. $(57,58)$

484 Between both assessments it was revealed that the length of culture time for the 485 endothelium still had the largest impact on model performance regardless of additives (Fig. 6). 486 Based on this finding it is possible that due to the influence the additives have on the 487 endothelium the HBEC-5i cells are differentiating before reaching confluency which is not 488 sustainable through the length of culture. This phenomenon could also explain why the effects of 489 additives appear to be more effective in $\mathrm{DOE}_{\mathrm{M} 2}$, culturing for 5 or 7 days post endothelial 490 plating, as the differentiation effects may be occurring earlier and not maintained through culture 491 times for DOE $\mathrm{M}_{1}$. A way to improve on this would be to include HBEC-5i seeding density as a 492 factor in further assessments of medium additives. With the trends of DOE $\mathrm{P}$ establishing the 493 positive impacts higher seeding densities have on model tightness, seeding at a higher density 494 (greater than the optimized 80,000 cells $/ \mathrm{cm}^{2}$ ) with differentiation inducing medium supplements 495 may result in the tightest barrier formed and additionally reduce culturing time. An alternative 496 would be to continue with optimized conditions of DOEP and include time of addition as a factor 497 in further studies by introducing additives after the HBEC-5i have been in culture for more than 49824 hours.

499 The influence of the medium additives may also extend beyond paracellular tightness. 500 Hydrocortisone has been shown to increase barrier tightness through the upregulation of tight 501 junction proteins, but has also been demonstrated to induce efflux transporter 
expression. $(39,69,70)$ Expression and function of $\mathrm{ABC}$ efflux transporters, specifically BCRP and P-gp, was also demonstrated to be influenced by the release of tumor necrosis factor- $\alpha$ (TNF- $\alpha$ ) and subsequent inflammatory responses. $(39,70,71)$ However, hydrocortisone is a glucocorticoid that has been demonstrated to impact P-gp and BCRP expression by inducing anti-inflammatory responses. Therefore, in addition to the impact on paracellular tightness, the induction of efflux transporter expression should also be assessed by evaluating the time of addition of hydrocortisone to the culture medium.

The increase in physiological relevance of adding additional cell types of the NVU in direct contact with $\mathrm{BBB}$ endothelium provides increased barrier restrictive properties in comparison to the endothelium alone. Additionally, including both supporting cell types (astrocytes and pericytes) in direct contact with HBEC-5i cells results in increased barrier tightness compared to direct contact cocultures (astrocyte- or pericyte-HBEC 5i combinations alone). This finding suggests that including both the astrocytes and pericytes in in vitro models further synergistically enhances the properties of the BBB in addition to better representing the in vivo NVU. The inductive effects of astrocytes and pericytes and their roles in BBB maintenance have been well established; however, many of the models used for in vitro BBB permeability screening do not consider the direct contact the different cell types have with one another in vivo. By seeding astrocytes, pericytes, and the endothelium directly atop one another this model better mimics the $20 \mathrm{~nm}$ distance between the cell types due to the presence of the basal lamina that is seen in vivo.(22) Although indirect plating methods with cell types cultured on opposite sides of a $10 \mu \mathrm{m}$ thick filter support also provide increased barrier properties over endothelial monocultures, the direct contact triculture is more physiologically relevant to the in vivo BBB that is observed in the NVU and does not require manipulation of the Transwell ${ }^{\circledR}$ 
system and potentially is more amenable to automation for higher capacity throughput screening assays.

Paracellular permeants of increasing hydrodynamic radius were selected to evaluate the tight junction formation in the direct contact model. With increasing marker size, there is a related decrease in paracellular permeability due to the size of the molecule in relation to the pore size of the tight junctions formed between adjacent endothelial cells. Permeability of $\left[{ }^{14} \mathrm{C}\right]-$ PEG-4000 (15.9 $\AA$ ) is the lowest of all markers used as expected followed by $\left[{ }^{14} \mathrm{C}\right]$-inulin $(10 \AA)$. In studies with the optimized direct contact triculture model, the permeability of $\left[{ }^{14} \mathrm{C}\right]$-sucrose (5.2 $\AA$ ) is faster than that of the smaller $\left[{ }^{14} \mathrm{C}\right]$-mannitol $(4.3 \AA)$, which is opposite of what would be expected based on molecule size alone.(59-61) One possible explanation is that the relative size of the two markers is small in comparison to the paracellular pore radius in the triculture model, which would lead to issues in elucidating the differences in their respective permeation rates as they both traverse relatively fast. Alternatively, sucrose, a disaccharide of a fructose and glucose molecule linked via glycosidic bond, may serve as a substrate for active or facilitative nutrient transporters. For example, glucose permeation across the BBB has been reported to be modulated by several nutrient transporters, in particular the facilitative Glucose Transporter 1 (GLUT1) that is highly expressed in both BMECs and astrocytes.(72,73) Several neurotherapeutics utilize a pro-drug approach where the agent is conjugated to glucose in an effort to enhance brain parenchymal exposure via GLUT1.(72,74) Based on the structure of sucrose, the idea that there is some degree of nutrient transporter activity of the purported paracellular marker via the GLUT1 transporter is feasible. Therefore, we posit that the observed permeation rate for sucrose could be higher due to a potential transporter contribution that is not available for $\left[{ }^{14} \mathrm{C}\right]$-mannitol in the optimized direct contact triculture. This theory is further 
548 exacerbated by the presence of astrocytes and pericytes on the apical side of the Transwell ${ }^{\circledR}$ in

549 the direct contact triculture since both of these cell types have reported expression of GLUT1.

550 The potential for GLUT1 mediated transport and a potential increase the permeation of $\left[{ }^{14} \mathrm{C}\right]-$

551 sucrose in the apical to basolateral direction in comparison to indirect in vitro models requires

552 further investigation. Future studies might focus on delineating the effects GLUT1, a related

553 transporter, with co-administration of transporter inhibitors, or with GLUT isoform transfected

554 HBEC-5i cells.

555 The functional activity of ATP-Binding Cassette efflux transporters, with the most 556 prevalent isoform being $\mathrm{P}-\mathrm{gp}$, in BMECs is a key characteristic of the in vivo BBB. $\mathrm{P}-\mathrm{gp}, \mathrm{BCRP}$, 557 and related multidrug resistance conferring efflux transporters function to prevent xenobiotics 558 from permeating into the brain parenchyma with a broad substrate affinity and capacity. 559 Rhodamine-123 (R123) is a commonly used P-gp substrate to assess functional activity in the 560 presence or absence of an inhibitor. Elacridar is a third generation P-gp inhibitor and has been 561 reported to have among the highest specificity and potency for P-gp inhibition within the class of 562 agents.(75) We observed that the presence of elacridar resulted in an increase in R123 563 permeability across the direct contact triculture, suggesting that P-gp is functionally present in 564 the optimized model. In these studies, R123 permeation was only assessed in the apical to 565 basolateral direction. Additional studies to elucidate P-gp function can include bi-directional 566 permeability assessment as well as cellular accumulation. However, given that P-gp is expressed 567 in both the HBEC-5i and astrocyte cell types in direct contact, the assessment of P-gp function 568 and expression would require more in depth studies focused on delineating the impact of P-gp in 569 each cell and in combination. This is particularly true given the fact that astrocytes have also 
570 been reported to express P-gp, which may further obfuscate P-gp assessment of the endothelium 571 alone.(76)

572 In addition to limiting paracellular permeation of hydrophilic solutes and potentially P-gp 573 substrates, we theorized that a well-established in vitro model of the BBB found in the NVU 574 should have an enhanced ability to differentiate between in vivo demonstrated high and low brain 575 permeating compounds. In vitro permeability screening models capable of predicting in vivo 576 permeation rates in order to rank new chemical entities is essential to facilitate compound 577 advancement with translation as the aim. $(77,78)$ A number of positive and negative permeants 578 were selected to assess the utility of the direct contact triculture. Amino acids and related 579 analogues (e.g. $\gamma$-aminobutyric acid or GABA) play a critical role in maintaining brain 580 homeostasis and modulating function. Here we selected L-histidine as an amino acid that is 581 actively transported in a stereospecific manner across the BBB by amino acid transporters and 582 potentially Peptide Histidine Transporter 1.(60,79) However, L-histidine is a small water soluble 583 molecule that can potentially permeate in vitro models to an extent via the paracellular pathway. 584 Hence, the paracellular route cannot be ignored as it may contribute to a higher permeation rate 585 of L-histidine in comparison to other transporter specific markers. Caffeine was also selected as 586 a small hydrophilic psychostimulant that has been demonstrated to permeate the in vivo BBB, 587 and we demonstrated its permeation across the direct contact triculture model.(80) 588 Carbamazepine was selected as it is an anticonvulsant commonly used as a BBB positive marker 589 and to our knowledge has not been shown to possess significant P-gp affinity. $(81,82)$ In addition 590 to R123, permeability of P-gp substrates colchicine and digoxin were assessed in the optimized 591 model. The differences in permeation rates for separate P-gp substrates can be attributed to the 592 broad substrate affinities and capacities of the efflux transporters and their relative expression 
593 levels. Further studies can be performed to assess the effect of P-gp inhibition on the permeation

594 of these substrates as well as inhibition of other efflux transporters such as BCRP as there is also

595 fairly significant substrate overlap across several efflux transporter isoforms. Clozapine is an

596 antipsychotic that has been shown to be highly metabolized and may potentially inhibit P-

597 gp. $(69,83)$ Clozapine metabolites have also been demonstrated to have high BBB permeation,

598 where additional studies using LC-mass spectrometry analysis and longer incubation time could

599 be performed to elucidate the metabolic fate in the optimized triculture model.(83) Although, it is

600 important to note that there were no metabolite peaks observed in the chromatograms during the

601 time course of this study. Lastly, prazosin is a BCRP substrate that proved to have the lowest

602 permeability of the selected markers. The low permeation of prazosin across the in vitro

603 triculture model potentially suggests that functional BCRP activity is greater than that of P-gp or

604 other efflux transporters, however further studies need to be performed to delineate the effects.

605 The observed ranking of high and low BBB permeating compounds is ordered in a similar 606 fashion to what has been seen by others both in vitro and in vivo. $(84,85)$ The observed

607 permeability of a small library of compounds across the optimized direct contact triculture model

608 suggests that it is a useful tool for further assessment of BBB permeation of new chemical

609 entities as well understanding of the synergistic effects of direct cell-cell contacts.

610 Conclusion

611

Herein, we have established an enhanced physiologically relevant in vitro model of the

612 BBB by culturing the astrocytes, pericytes, and HBEC-5i cells in a layered, direct contact

613 manner similar to the in vivo BBB that is comprised as part of the NVU. We provide supporting

614 evidence that apical cell layering removes the physical filter barrier observed in conventional

615 triculture models and supports the potential of synergistic interactions occurring to provide a

616 phenotype closer to the NVU. In addition, to our knowledge we are one of the first laboratories 
617 to utilize a three-stage multifactorial DOE based approach to expedite optimization of a BBB in 618 vitro model. It is recommended that additional DOE based studies be performed to develop 619 analogous models to mimic different pathologies of the brain, for example neurodevelopmental 620 changes or neurodegenerative effects on the BBB with primary or proliferative cell lines.

622 tightening the brain microvessel endothelium that lines the capillaries, separates the blood from 623 the neuronal environment, and maintains homeostasis. While screening models in the presence of 624 astrocytes and pericytes in indirect contact to the BMECs have been developed, we postulated 625 that direct contact of these cells, as found in vivo, would more adequately enhance in vitro-in 626 vivo comparative studies. The direct layered culturing approach should enhance the synergistic 627 effects by removing physical barriers and providing proximity so that secreted soluble factors 628 and their effects on the regulation of the BMEC phenotype should be enhanced without added 629 dilution and diffusion. Additionally, the ability for the model to rank established high and low 630 brain permeating compounds alludes to its potential for BBB permeability screening of new 631 chemical entities. This study also demonstrates the feasibility of using an informed DOE based 632 approach to expedite culture development and can be further expanded for additional 633 applications. Taken together, the direct contact triculture developed within appears to provide 634 increased barrier properties that we theorize is attributable through facilitating adequate crosstalk 635 between the three major cell types of the BBB that aids in the formation of the in vivo NVU. The 636 findings of this work open the door for continued investigation of the roles of each $\mathrm{BBB}$ and 637 potentially NVU cell type and its influence on barrier properties, as well as the establishment of 638 a fully human, physiologically relevant in vitro model that can be used for moderate throughput 639 screening to rank order potential neurotherapeutic compounds. 


\section{Abbreviations}

641 ABC - ATP binding cassette

642 BBB - blood brain barrier

643 BCRP - breast cancer resistant protein

644 BMEC - brain microvessel endothelial cell

645 DMEM/F-12 - Dulbecco's Modified Eagle Medium/Nutrient Mixture F-12

646 DMSO - dimethylsulfoxide

647 DOE - design of experiments

648 ECGS - endothelial cell growth supplement

649 ECM - extracellular matrix

650 FBS - fetal bovine serum

651 FITC - Fluorescein isothiocyanate

652 GLUT-1 - glucose transporter 1

653 HBSS - Hank's balanced salt solution

654 HBEC-5i - human brain endothelial cell

655 hCMEC/D3 - human cerebral microvessel endothelial cell

656 HEPES - 2-[4-(2-hydroxyethyl)piperazin-1-yl]ethanesulfonic acid

657 ICAM-1 - intercellular adhesion molecule 1

$658 \quad$ NVU - neurovascular unit

659 OFAT - one factor at a time

660 Papp - apparent permeability

661 PBS - phosphate buffered saline

662 PDGF-B - platelet-derived growth factor B 
663 Peff - effective permeability

664 PECAM-1 - platelet endothelial cell adhesion molecule 1

665 P-gp - p-glycoprotein

666 PLL - poly-L-lysine

667 R123 - rhodamine 123

668 TEER - transendothelial electrical resistance

669 TGF- $\beta$ - transforming growth factor- $\beta$

670 TNF- $\alpha-$ tumor necrosis factor- $\alpha$

671 VCAM-1 - vascular adhesion molecule 1

672 ZO-1 - zonula occluden 1

673 Declarations

674 Ethics approval and consent to participate

675 'Not applicable'

676 Consent for publication

677 'Not applicable'

678 Availability of data and materials

679 All data generated or analyzed during this study are included in this published article and its 680 Additional Files.

681 Competing interest

682 Authors KL and GK are inventors under US Patent No. 10877026 which covers the work 683 presented in this publication.

$684 \quad$ Funding 
685 This work was supported in part by Environmental Protection Agency OSAPE Star Grant \#RD$68684002701-0$.

\section{Authors' contributions}

688 KL designed and performed the experiments. KL and GK analyzed the data and drafted, 689 reviewed, and approved the manuscript.

\section{Acknowledgements}

691 The authors would like to acknowledge their co-inventors of US Patent No. 10877026 Dr.

692 Christopher D. Kulczar, Dr. Monika Lavan, and Dr. Aimable Ngendahimana for their 693 contributions to the establishment of this model.

\section{Figure Captions}

695 Figure 1. Cross sectional depiction of the Blood-Brain Barrier within the neurovascular unit 696 (NVU) with the endothelium (BMECs) lining the capillary, pericytes embedded within the basal 697 lamina, astrocytes having nearly full coverage of the BMECs and surrounding pericytes, and 698 neurons in close contact with the astrocytes (left). The direct contact triculture model on the 699 apical surface of a Transwell ${ }^{\circledR}$ filter support mimicking the in vivo NVU. Astrocytes are seeded 700 first on the filter, followed by pericytes, then BMECs to generate a fully apical, direct contact 701 triculture model (right).

702 Figure 2. $\mathrm{P}_{\text {app }}$ and $\mathrm{P}_{\text {eff }}$ of $4 \mathrm{kD}$ FITC-Dextran across different direct contact triculture conditions 703 of $\mathrm{DOE}_{\mathrm{P}}$. All $\mathrm{DOE}_{\mathrm{P}}$ selected conditions were performed as $\mathrm{n}=1$ for a rapid evaluation of the 704 different parameter combinations. Condition 13 was compromised and permeability was not 705 performed, data point was excluded from statistical analysis. 
Figure 3. $\mathrm{P}_{\text {eff }}$ of $4 \mathrm{kD}$ FITC-Dextran for $\mathrm{DOE}_{\mathrm{P}}$ separated by factor and further by day of study

707

708

709

710

711

712

713

714

715

716

717

718

719

720

721

722

723

724

725

726

727

728

729

showing relative trends of factor levels at increasing length of culture. All conditions are represented by single data points across the graph, $n=1$.

Figure 4. JMP 13.2 Prediction Profiler generated based on maximizing desirability for $\mathrm{P}_{\text {eff }}$ based on DOE P. Optimal plating conditions 20,000 cells $/ \mathrm{cm}^{2}$ astrocytes and pericytes, 80,000 cells $/ \mathrm{cm}^{2}$ HBEC-5i, Matrigel, and 9 days of endothelial growth. Predicted $\mathrm{P}_{\text {eff }}$ of $2.4 \times 10^{-6} \mathrm{~cm} / \mathrm{sec}$ for optimal conditions.

Figure 5. JMP 13.2 Prediction Profiler generated based on maximizing desirability for $\mathrm{P}_{\text {eff }}$ of DOE $_{\mathrm{M} 1}$. Optimal medium conditions $15 \mathrm{mM}$ HEPES, $1 \mathrm{mM} \mathrm{Ca}^{2+}$, and $10 \mu \mathrm{M}$ retinoic acid at 9 days of endothelial growth. Predicted $\mathrm{P}_{\mathrm{eff}}$ of $7.0 \times 10^{-6} \mathrm{~cm} / \mathrm{sec}$ for optimal conditions.

Figure 6. JMP 13.2 Prediction Profiler generated based on maximizing desirability for $\mathrm{P}_{\text {eff }}$ of $\mathrm{DOE}_{\mathrm{M} 2}$. Optimal medium conditions $10 \mu \mathrm{M}$ dexamethasone, $10 \mu \mathrm{M}$ retinoic acid, $10 \mathrm{mM} \mathrm{LiCl,}$ through 7 days of endothelial culture. Predicted $P_{\text {eff }}$ of $8.8 \times 10^{-6} \mathrm{~cm} / \mathrm{sec}$ for optimal conditions. Figure 7. Optimized Triculture Permeability. (A) Effective permeability ( $\left.\mathrm{P}_{\text {eff }}\right)$ of 4 kD FITCdextran across an HBEC-5i monoculture, pericyte-HBEC-5i direct contact coculture, astrocyteHBEC-5i direct contact coculture, and optimized direct contact triculture. Statistical analysis was performed with one-way ANOVA and Tukey-Kramer post-hoc test. Error bars represent one standard deviation $(\mathrm{n}=3) .{ }^{*}, \mathrm{p}<0.05$ and ${ }^{*}, \mathrm{p}<0.01$. (B) Apparent permeability of radiolabeled paracellular markers $\left[{ }^{14} \mathrm{C}\right]$-sucrose. $\left[{ }^{14} \mathrm{C}\right]$-mannitol, $\left[{ }^{14} \mathrm{C}\right]$-inulin, and $\left[{ }^{14} \mathrm{C}\right]$-PEG-4000 across the optimized direct contact triculture. Error bars represent one standard deviation $(n=3)$. (C) Apparent permeability of P-gp substrate rhodamine 123 (R123) in the presence and absence of P-gp inhibitor elacridar across the optimized direct contact triculture. Assays were run in triplicate and subjected to Student's $t$-test. Significant difference is indicated by $*, \mathrm{p}<0.05$ and $* *, \mathrm{p}<0.01$. Error bars represent one standard deviation $(n=3)$. 
Figure 8. Apparent permeability of BBB positive (L-histidine, carbamazepine, and rhodamine

123 in the presence of P-gp inhibitor elacridar) and negative (colchicine, rhodamine 123, digoxin, clozapine, and prazosin) permeants across the optimized direct contact triculture.

Assays were performed in triplicate. Error bars represent one standard deviation $(n=3)$.

\section{References}

1. Pardridge WM. Why is the global CNS pharmaceutical market so under-penetrated? Drug Discov Today. 2002 Jan 1;7(1):5-7.

2. Gribkoff VK, Kaczmarek LK. The Need for New Approaches in CNS Drug Discovery: Why Drugs Have Failed, and What Can Be Done to Improve Outcomes. Neuropharmacology. 2017 Jul 1;120:11-9.

3. Kesselheim AS, Hwang TJ, Franklin JM. Two decades of new drug development for central nervous system disorders. Nat Rev Drug Discov. 2015 Dec;14(12):815-6.

4. Abbott NJ, Patabendige AAK, Dolman DEM, Yusof SR, Begley DJ. Structure and function of the blood-brain barrier. Neurobiol Dis. 2010 Jan;37(1):13-25.

5. Abbott NJ. Blood-brain barrier structure and function and the challenges for CNS drug delivery. J Inherit Metab Dis. 2013 May;36(3):437-49.

6. Serlin Y, Shelef I, Knyazer B, Friedman A. Anatomy and Physiology of the Blood-Brain Barrier. Semin Cell Dev Biol. 2015 Feb;38:2-6.

7. Weiss N, Miller F, Cazaubon S, Couraud P-O. The blood-brain barrier in brain homeostasis and neurological diseases. Biochim Biophys Acta BBA - Biomembr. 2009 Apr;1788(4):842-57.

8. Bauer H-C, Krizbai IA, Bauer H, Traweger A. "You Shall Not Pass"-tight junctions of the blood brain barrier. Front Neurosci. 2014;8:392.

9. Haseloff RF, Dithmer S, Winkler L, Wolburg H, Blasig IE. Transmembrane proteins of the tight junctions at the blood-brain barrier: structural and functional aspects. Semin Cell Dev Biol. 2015 Feb;38:16-25.

10. Wolburg H, Lippoldt A. Tight junctions of the blood-brain barrier: development, composition and regulation. Vascul Pharmacol. 2002 Jun;38(6):323-37.

11. Löscher W, Potschka H. Blood-brain barrier active efflux transporters: ATP-binding cassette gene family. NeuroRx J Am Soc Exp Neurother. 2005 Jan;2(1):86-98.

12. Polli JW, Olson KL, Chism JP, John-Williams LS, Yeager RL, Woodard SM, et al. An Unexpected Synergist Role of P-Glycoprotein and Breast Cancer Resistance Protein on the 
Central Nervous System Penetration of the Tyrosine Kinase Inhibitor Lapatinib (N-\{3Chloro-4-[(3-fluorobenzyl)oxy]phenyl $\}-6-[5-(\{[2-($ methylsulfonyl)ethyl]amino $\}$ methyl)-2furyl]-4-quinazolinamine; GW572016). Drug Metab Dispos. 2009 Feb 1;37(2):439-42.

13. Abbott NJ, Rönnbäck L, Hansson E. Astrocyte-endothelial interactions at the blood-brain barrier. Nat Rev Neurosci. 2006 Jan;7(1):41-53.

14. Bouchaud C, Le Bert M, Dupouey P. Are close contacts between astrocytes and endothelial cells a prerequisite condition of a blood-brain barrier? The rat subfornical organ as an example. Biol Cell. 1989;67(2):159-65.

15. Bushong EA, Martone ME, Jones YZ, Ellisman MH. Protoplasmic astrocytes in CA1 stratum radiatum occupy separate anatomical domains. J Neurosci Off J Soc Neurosci. 2002 Jan 1;22(1):183-92.

16. Halassa MM, Fellin T, Takano H, Dong J-H, Haydon PG. Synaptic islands defined by the territory of a single astrocyte. J Neurosci Off J Soc Neurosci. 2007 Jun 13;27(24):6473-7.

17. Wolburg H, Wolburg-Buchholz K, Fallier-Becker P, Noell S, Mack AF. Chapter one Structure and Functions of Aquaporin-4-Based Orthogonal Arrays of Particles. In: Jeon KW, editor. International Review of Cell and Molecular Biology [Internet]. Academic Press; 2011 [cited 2018 Feb 12]. p. 1-41. Available from: http://www.sciencedirect.com/science/article/pii/B9780123860439000013

18. Haseloff RF, Blasig IE, Bauer HC, Bauer H. In search of the astrocytic factor(s) modulating blood-brain barrier functions in brain capillary endothelial cells in vitro. Cell Mol Neurobiol. 2005 Feb;25(1):25-39.

19. Lee S-W, Kim WJ, Choi YK, Song HS, Son MJ, Gelman IH, et al. SSeCKS regulates angiogenesis and tight junction formation in blood-brain barrier. Nat Med. 2003 Jul;9(7):900-6.

20. Argaw AT, Gurfein BT, Zhang Y, Zameer A, John GR. VEGF-mediated disruption of endothelial CLN-5 promotes blood-brain barrier breakdown. Proc Natl Acad Sci U S A. 2009 Feb 10;106(6):1977-82.

21. Alvarez JI, Katayama T, Prat A. Glial influence on the Blood Brain Barrier. Glia. 2013 Dec;61(12):1939-58.

22. Mathiisen TM, Lehre KP, Danbolt NC, Ottersen OP. The perivascular astroglial sheath provides a complete covering of the brain microvessels: An electron microscopic 3D reconstruction. Glia. 2010 Jul 1;58(9):1094-103.

23. Winkler EA, Bell RD, Zlokovic BV. Central nervous system pericytes in health and disease. Nat Neurosci. 2011 Oct 26;14(11):1398-405.

24. Daneman R, Zhou L, Kebede AA, Barres BA. Pericytes are required for blood-brain barrier integrity during embryogenesis. Nature. 2010 Nov 25;468(7323):562-6. 
25. Gaengel K, Genové G, Armulik A, Betsholtz C. Endothelial-mural cell signaling in vascular development and angiogenesis. Arterioscler Thromb Vasc Biol. 2009 May;29(5):630-8.

26. Hawkins BT, Davis TP. The Blood-Brain Barrier/Neurovascular Unit in Health and Disease. Pharmacol Rev. 2005 Jun 1;57(2):173-85.

27. Baeten KM, Akassoglou K. Extracellular Matrix and Matrix Receptors in Blood-Brain Barrier Formation and Stroke. Dev Neurobiol. 2011 Nov;71(11):1018-39.

28. Weksler BB, Subileau EA, Perrière N, Charneau P, Holloway K, Leveque M, et al. Bloodbrain barrier-specific properties of a human adult brain endothelial cell line. FASEB J Off Publ Fed Am Soc Exp Biol. 2005 Nov;19(13):1872-4.

29. Weksler B, Romero IA, Couraud P-O. The hCMEC/D3 cell line as a model of the human blood brain barrier. Fluids Barriers CNS. 2013 Mar 26;10(1):16.

30. Helms HC, Abbott NJ, Burek M, Cecchelli R, Couraud P-O, Deli MA, et al. In vitro models of the blood-brain barrier: An overview of commonly used brain endothelial cell culture models and guidelines for their use. J Cereb Blood Flow Metab Off J Int Soc Cereb Blood Flow Metab. 2016 May;36(5):862-90.

31. Tai LM, Reddy PS, Lopez-Ramirez MA, Davies HA, Male DK, Male ADK, et al. Polarized P-glycoprotein expression by the immortalised human brain endothelial cell line, hCMEC/D3, restricts apical-to-basolateral permeability to rhodamine 123. Brain Res. 2009 Oct 6;1292:14-24.

32. Biemans EALM, Jäkel L, de Waal RMW, Kuiperij HB, Verbeek MM. Limitations of the $\mathrm{hCMEC/D} 3$ cell line as a model for $\mathrm{A} \beta$ clearance by the human blood-brain barrier. J Neurosci Res. 2017 Jul;95(7):1513-22.

33. Urich E, Lazic SE, Molnos J, Wells I, Freskgård P-O. Transcriptional profiling of human brain endothelial cells reveals key properties crucial for predictive in vitro blood-brain barrier models. PloS One. 2012;7(5):e38149.

34. Dorovini-Zis K, Prameya R, Bowman PD. Culture and characterization of microvascular endothelial cells derived from human brain. Lab Investig J Tech Methods Pathol. 1991 Mar;64(3):425-36.

35. Wassmer SC, Combes V, Candal FJ, Juhan-Vague I, Grau GE. Platelets Potentiate Brain Endothelial Alterations Induced by Plasmodium falciparum. Infect Immun. 2006 Jan 1;74(1):645-53.

36. Wassmer SC, Cianciolo GJ, Combes V, Grau GE. Inhibition of Endothelial Activation: A New Way to Treat Cerebral Malaria? PLoS Med [Internet]. 2005 Sep [cited 2018 Apr 19];2(9). Available from: https://www.ncbi.nlm.nih.gov/pmc/articles/PMC1188254/ 
37. Jambou R, Combes V, Jambou M-J, Weksler BB, Couraud P-O, Grau GE. Plasmodium falciparum adhesion on human brain microvascular endothelial cells involves transmigration-like cup formation and induces opening of intercellular junctions. PLoS Pathog. 2010 Jul 29;6(7):e1001021.

38. Jiang W, Huang W, Chen Y, Zou M, Peng D, Chen D. HIV-1 Transactivator Protein Induces ZO-1 and Neprilysin Dysfunction in Brain Endothelial Cells via the Ras Signaling Pathway [Internet]. Oxidative Medicine and Cellular Longevity. 2017 [cited 2018 Nov 29]. Available from: https://www.hindawi.com/journals/omcl/2017/3160360/

39. Puech C, Hodin S, Forest V, He Z, Mismetti P, Delavenne X, et al. Assessment of HBEC-5i endothelial cell line cultivated in astrocyte conditioned medium as a human blood-brain barrier model for ABC drug transport studies. Int J Pharm. 2018 Nov 15;551(1):281-9.

40. Puech C, Delavenne X, He Z, Forest V, Mismetti P, Perek N. Direct oral anticoagulants are associated with limited damage of endothelial cells of the blood-brain barrier mediated by the thrombin/PAR-1 pathway. Brain Res. 2019 May 20;

41. Dohgu S, Takata F, Yamauchi A, Nakagawa S, Egawa T, Naito M, et al. Brain pericytes contribute to the induction and up-regulation of blood-brain barrier functions through transforming growth factor-beta production. Brain Res. 2005 Mar 21;1038(2):208-15.

42. Zozulya A, Weidenfeller C, Galla H-J. Pericyte-endothelial cell interaction increases MMP9 secretion at the blood-brain barrier in vitro. Brain Res. 2008 Jan 16;1189:1-11.

43. Demeuse P, Kerkhofs A, Struys-Ponsar C, Knoops B, Remacle C, van den Bosch de Aguilar P. Compartmentalized coculture of rat brain endothelial cells and astrocytes: a syngenic model to study the blood-brain barrier. J Neurosci Methods. 2002 Nov 15;121(1):21-31.

44. Thanabalasundaram G, El-Gindi J, Lischper M, Galla H-J. Methods to assess pericyteendothelial cell interactions in a coculture model. Methods Mol Biol Clifton NJ. 2011;686:379-99.

45. Li G, Simon MJ, Cancel LM, Shi Z-D, Ji X, Tarbell JM, et al. Permeability of endothelial and astrocyte cocultures: in vitro blood-brain barrier models for drug delivery studies. Ann Biomed Eng. 2010 Aug;38(8):2499-511.

46. Thomsen LB, Burkhart A, Moos T. A Triple Culture Model of the Blood-Brain Barrier Using Porcine Brain Endothelial cells, Astrocytes and Pericytes. PloS One. 2015;10(8):e0134765.

47. Wuest DM, Wing AM, Lee KH. Membrane configuration optimization for a murine in vitro blood-brain barrier model. J Neurosci Methods. 2013 Jan 30;212(2):211-21.

48. Hatherell K, Couraud P-O, Romero IA, Weksler B, Pilkington GJ. Development of a threedimensional, all-human in vitro model of the blood-brain barrier using mono-, co-, and tricultivation Transwell models. J Neurosci Methods. 2011 Aug 15;199(2):223-9. 
49. McConnell HL, Kersch CN, Woltjer RL, Neuwelt EA. The Translational Significance of the Neurovascular Unit. J Biol Chem. 2017 Jan 20;292(3):762-70.

50. Malina KC-K, Cooper I, Teichberg VI. Closing the gap between the in-vivo and in-vitro blood-brain barrier tightness. Brain Res. 2009 Aug 11;1284:12-21.

51. Kulczar C, Lubin KE, Lefebvre S, Miller DW, Knipp GT. Development of a direct contact astrocyte-human cerebral microvessel endothelial cells blood-brain barrier coculture model. J Pharm Pharmacol. 2017 Dec;69(12):1684-96.

52. Förster C, Burek M, Romero IA, Weksler B, Couraud P-O, Drenckhahn D. Differential effects of hydrocortisone and $\mathrm{TNF} \alpha$ on tight junction proteins in an in vitro model of the human blood-brain barrier. J Physiol. 2008 Apr 1;586(Pt 7):1937-49.

53. Paolinelli R, Corada M, Ferrarini L, Devraj K, Artus C, Czupalla CJ, et al. Wnt Activation of Immortalized Brain Endothelial Cells as a Tool for Generating a Standardized Model of the Blood Brain Barrier In Vitro. PLOS ONE. 2013 Aug 5;8(8):e70233.

54. Brown RC, Davis TP. Calcium modulation of adherens and tight junction function: a potential mechanism for blood-brain barrier disruption after stroke. Stroke. 2002 Jun;33(6):1706-11.

55. De Bock M, Culot M, Wang N, da Costa A, Decrock E, Bol M, et al. Low extracellular $\mathrm{Ca} 2+$ conditions induce an increase in brain endothelial permeability that involves intercellular Ca2+ waves. Brain Res. 2012 Dec 3;1487:78-87.

56. Hue CD, Cho FS, Cao S, "Dale" Bass CR, Meaney DF, Morrison III B. Dexamethasone potentiates in vitro blood-brain barrier recovery after primary blast injury by glucocorticoid receptor-mediated upregulation of ZO-1 tight junction protein. J Cereb Blood Flow Metab. $2015 \mathrm{Jul} ; 35(7): 1191-8$.

57. Lippmann ES, Al-Ahmad A, Azarin SM, Palecek SP, Shusta EV. A retinoic acid-enhanced, multicellular human blood-brain barrier model derived from stem cell sources. Sci Rep. 2014 Feb 24;4:4160.

58. Mizee MR, Wooldrik D, Lakeman KAM, Hof B van het, Drexhage JAR, Geerts D, et al. Retinoic Acid Induces Blood-Brain Barrier Development. J Neurosci. 2013 Jan 23;33(4):1660-71.

59. Ghandehari H, Smith PL, Ellens H, Yeh PY, Kopecek J. Size-dependent permeability of hydrophilic probes across rabbit colonic epithelium. J Pharmacol Exp Ther. 1997 Feb;280(2):747-53.

60. Carl SM, Lindley DJ, Das D, Couraud PO, Weksler BB, Romero I, et al. ABC and SLC transporter expression and proton oligopeptide transporter (POT) mediated permeation across the human blood--brain barrier cell line, hCMEC/D3 [corrected]. Mol Pharm. 2010 Aug 2;7(4):1057-68. 
61. Sorensen M, Steenberg B, Knipp GT, Wang W, Steffansen B, Frokjaer S, et al. The effect of beta-turn structure on the permeation of peptides across monolayers of bovine brain microvessel endothelial cells. Pharm Res. 1997 Oct;14(10):1341-8.

62. NAIK P, CUCULLO L. In Vitro Blood-Brain Barrier Models: Current and Perspective Technologies. J Pharm Sci. 2012 Apr;101(4):1337-54.

63. Bernas MJ, Cardoso FL, Daley SK, Weinand ME, Campos AR, Ferreira AJG, et al. Establishment of primary cultures of human brain microvascular endothelial cells to provide an in vitro cellular model of the blood-brain barrier. Nat Protoc. 2010 Jul;5(7):1265-72.

64. Lacombe O, Videau O, Chevillon D, Guyot A-C, Contreras C, Blondel S, et al. In vitro primary human and animal cell-based blood-brain barrier models as a screening tool in drug discovery. Mol Pharm. 2011 Jun 6;8(3):651-63.

65. Knipp GT, Liu B, Audus KL, Fujii H, Ono T, Soares MJ. Fatty acid transport regulatory proteins in the developing rat placenta and in trophoblast cell culture models. Placenta. 2000 May;21(4):367-75.

66. Gaston JD, Bischel LL, Fitzgerald LA, Cusick KD, Ringeisen BR, Pirlo RK. Gene Expression Changes in Long-Term In Vitro Human Blood-Brain Barrier Models and Their Dependence on a Transwell Scaffold Material. J Healthc Eng [Internet]. 2017 [cited 2018 Apr 23];2017. Available from: https://www.ncbi.nlm.nih.gov/pmc/articles/PMC5727720/

67. Lai C-H, Kuo K-H. The critical component to establish in vitro BBB model: Pericyte. Brain Res Brain Res Rev. 2005 Dec 15;50(2):258-65.

68. Armulik A, Genové G, Mäe M, Nisancioglu MH, Wallgard E, Niaudet C, et al. Pericytes regulate the blood-brain barrier. Nature. 2010 Nov 25;468(7323):557-61.

69. Maines LW, Antonetti DA, Wolpert EB, Smith CD. Evaluation of the role of Pglycoprotein in the uptake of paroxetine, clozapine, phenytoin and carbamazapine by bovine retinal endothelial cells. Neuropharmacology. 2005 Oct 1;49(5):610-7.

70. Wedel-Parlow MV, Wölte P, Galla H-J. Regulation of major efflux transporters under inflammatory conditions at the blood-brain barrier in vitro. J Neurochem. 2009;111(1):1118.

71. Eisenblätter T, Galla H-J. A new multidrug resistance protein at the blood-brain barrier. Biochem Biophys Res Commun. 2002 May 17;293(4):1273-8.

72. Patching SG. Glucose Transporters at the Blood-Brain Barrier: Function, Regulation and Gateways for Drug Delivery. Mol Neurobiol. 2017 Mar;54(2):1046-77.

73. Morgello S, Uson RR, Schwartz EJ, Haber RS. The human blood-brain barrier glucose transporter (GLUT1) is a glucose transporter of gray matter astrocytes. Glia. 1995 May;14(1):43-54. 
74. Xiuli G, Meiyu G, Guanhua D. Glucose Transporter 1, Distribution in the Brain and in Neural Disorders: Its Relationship With Transport of Neuroactive Drugs Through the Blood-Brain Barrier. Biochem Genet. 2005 Apr 1;43(3):175-87.

75. Amin MdL. P-glycoprotein Inhibition for Optimal Drug Delivery. Drug Target Insights. 2013 Aug 19;7:27-34.

76. Zhang L, Ong WY, Lee T. Induction of P-glycoprotein expression in astrocytes following intracerebroventricular kainate injections. Exp Brain Res. 1999 Jun;126(4):509-16.

77. Wang Q, Rager JD, Weinstein K, Kardos PS, Dobson GL, Li J, et al. Evaluation of the MDR-MDCK cell line as a permeability screen for the blood-brain barrier. Int J Pharm. 2005 Jan 20;288(2):349-59.

78. Hidalgo IJ. Assessing the absorption of new pharmaceuticals. Curr Top Med Chem. 2001 Nov;1(5):385-401.

79. Yamakami J, Sakurai E, Sakurada T, Maeda K, Hikichi N. Stereoselective blood-brain barrier transport of histidine in rats. Brain Res. 1998 Nov 23;812(1-2):105-12.

80. Chen X, Ghribi O, Geiger JD. Caffeine protects against disruptions of the blood-brain barrier in animal models of Alzheimer's and Parkinson's disease. J Alzheimers Dis JAD. 2010;20(Suppl 1):S127-41.

81. Grewal GK, Kukal S, Kanojia N, Madan K, Saso L, Kukreti R. In Vitro Assessment of the Effect of Antiepileptic Drugs on Expression and Function of ABC Transporters and Their Interactions with ABCC2. Mol Basel Switz. 2017 Sep 29;22(10).

82. Potschka H, Fedrowitz M, Löscher W. Brain access and anticonvulsant efficacy of carbamazepine, lamotrigine, and felbamate in ABCC2/MRP2-deficient TR- rats. Epilepsia. 2003 Dec;44(12):1479-86.

83. Hellman K, Aadal Nielsen P, Ek F, Olsson R. An ex Vivo Model for Evaluating BloodBrain Barrier Permeability, Efflux, and Drug Metabolism. ACS Chem Neurosci. 2016 May 18;7(5):668-80.

84. Di Marco A, Gonzalez Paz O, Fini I, Vignone D, Cellucci A, Battista MR, et al. Application of an in Vitro Blood-Brain Barrier Model in the Selection of Experimental Drug Candidates for the Treatment of Huntington's Disease. Mol Pharm. 2019 May 6;16(5):2069-82.

85. Di Marco A, Vignone D, Gonzalez Paz O, Fini I, Battista MR, Cellucci A, et al. Establishment of an in Vitro Human Blood-Brain Barrier Model Derived from Induced Pluripotent Stem Cells and Comparison to a Porcine Cell-Based System. Cells. 2020 Apr 16;9(4). 


\section{$976 \quad$ Additional Files}

$977 \quad$ Additional File 1

978 Additional File 1.xlsx

979 Data Title: Conditions and $\mathrm{P}_{\text {eff }}$ of $4 \mathrm{kD}$ Dextran of $\mathrm{DOE}_{\mathrm{P}}$

980 Description: Contains full data set and run conditions of DOE that contributed to Fig. 2, Fig. 3,

981 and Fig. 4

$982 \quad$ Additional File 2

983 Additional File 2.xlsx

984 Data Title: Conditions and $\mathrm{P}_{\mathrm{eff}}$ of $4 \mathrm{kD}$ Dextran of $\mathrm{DOE}_{\mathrm{M} 1}$

985 Description: Contains full data set and run conditions of $\mathrm{DOE}_{\mathrm{M} 1}$ that contributed to Fig. 5

$986 \quad$ Additional File 3

987 Additional File 3.xlsx

988 Data Title: Conditions and $\mathrm{P}_{\mathrm{eff}}$ of $4 \mathrm{kD}$ Dextran of $\mathrm{DOE}_{\mathrm{M} 2}$

989 Description: Contains full data set and run conditions of $\mathrm{DOE}_{\mathrm{M} 2}$ that contributed to Fig. 6 


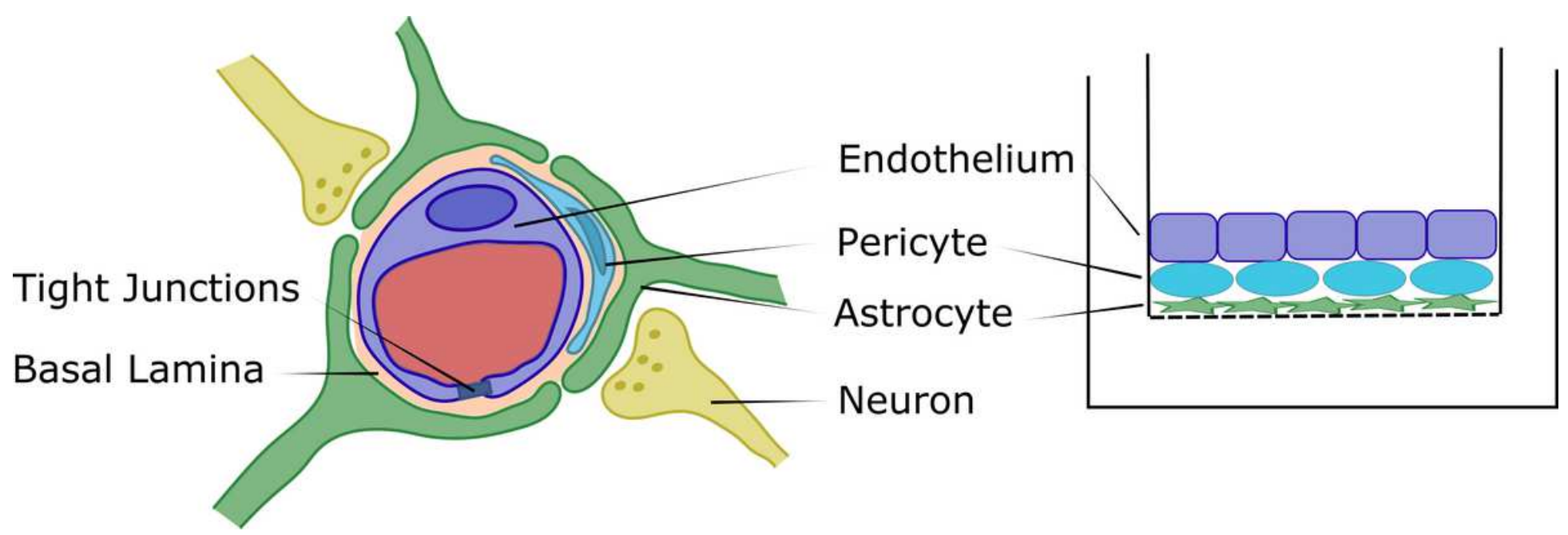

Figure 1

Cross sectional depiction of the Blood-Brain Barrier within the neurovascular unit (NVU) with the endothelium (BMECs) lining the capillary, pericytes embedded within the basal lamina, astrocytes having nearly full coverage of the BMECs and surrounding pericytes, and neurons in close contact with the astrocytes (left). The direct contact triculture model on the apical surface of a Transwell $\circledast$ filter support mimicking the in vivo NVU. Astrocytes are seeded first on the filter, followed by pericytes, then BMECs to generate a fully apical, direct contact triculture model (right).

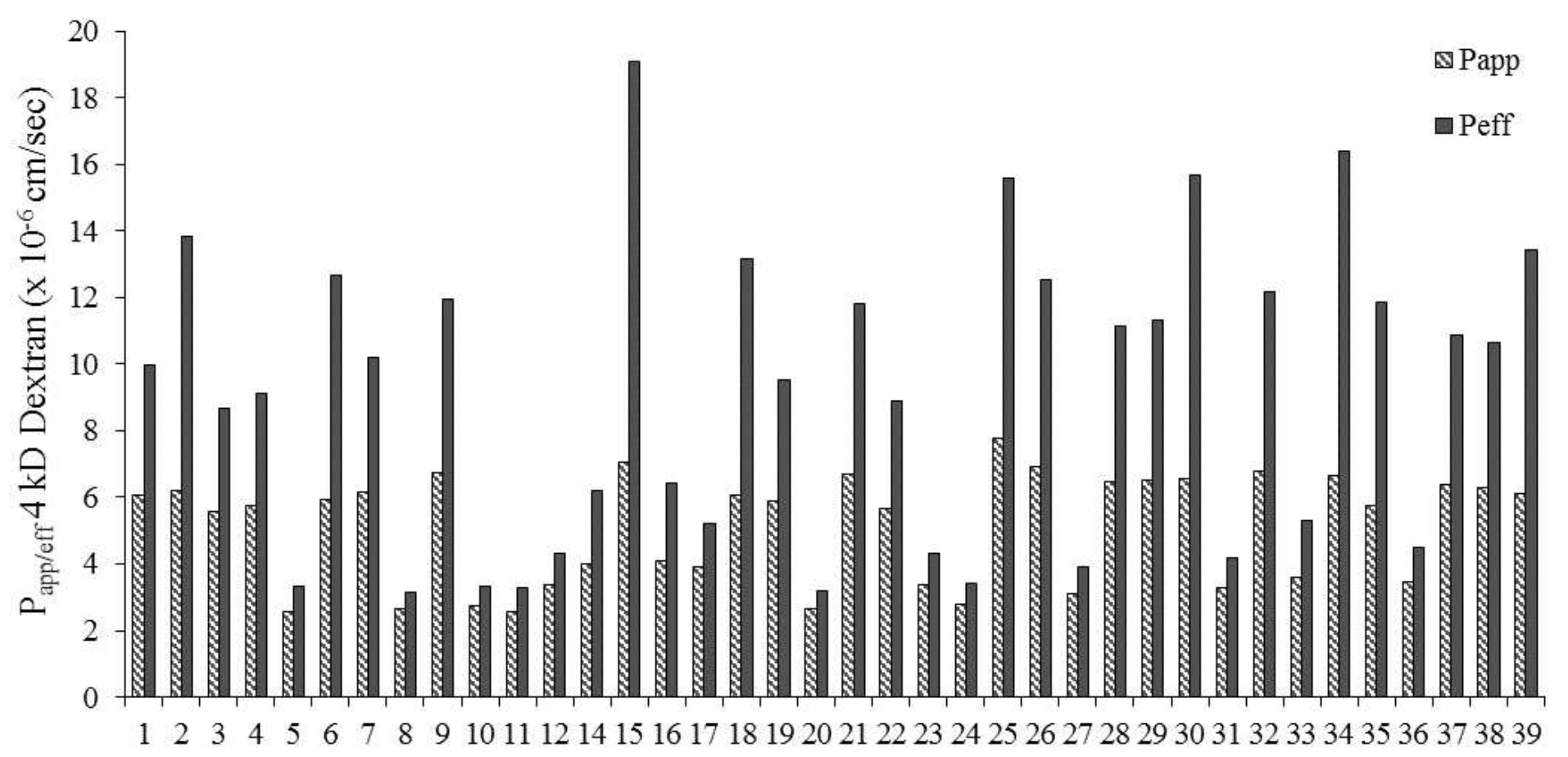

Figure 2 
Papp and Peff of 4 kD FITC-Dextran across different direct contact triculture conditions of DOEP. All DOEP selected conditions were performed as $n=1$ for a rapid evaluation of the different parameter combinations. Condition 13 was compromised and permeability was not performed, data point was excluded from statistical analysis.

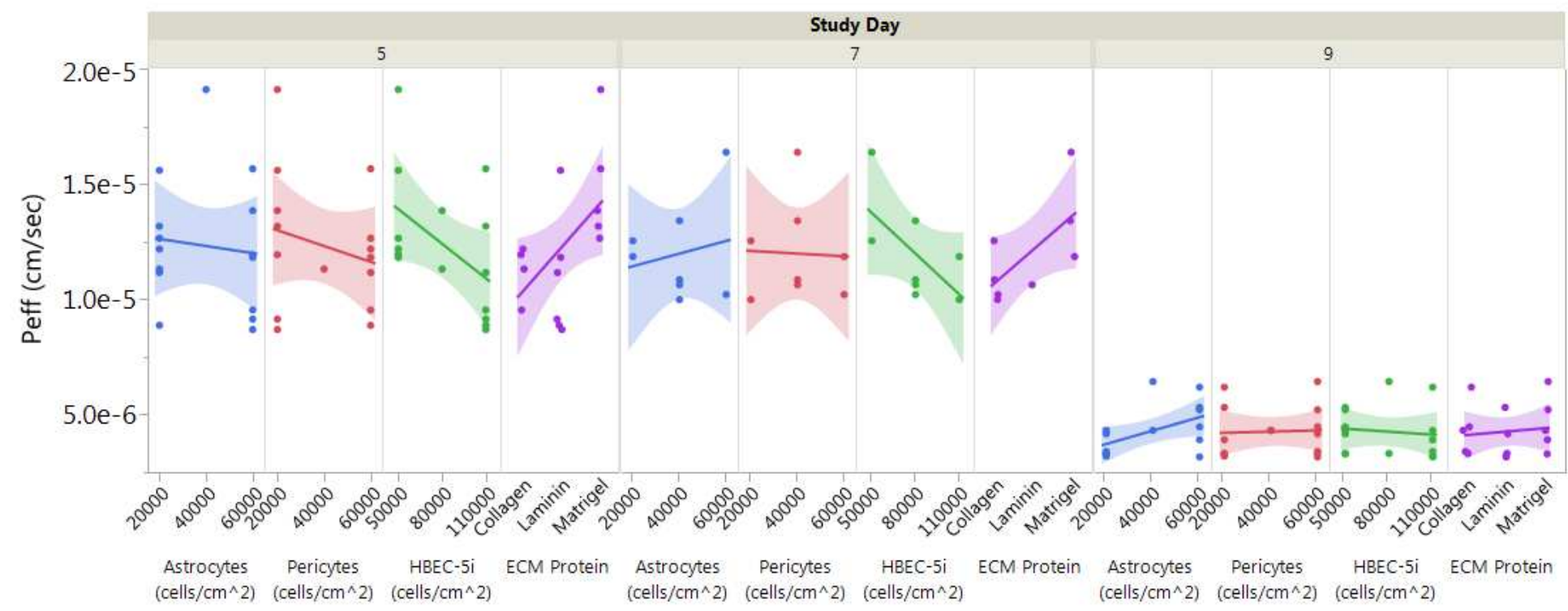

\section{Figure 3}

Peff of 4 kD FITC-Dextran for DOEP separated by factor and further by day of study showing relative trends of factor levels at increasing length of culture. All conditions are represented by single data points across the graph, $\mathrm{n}=1$.

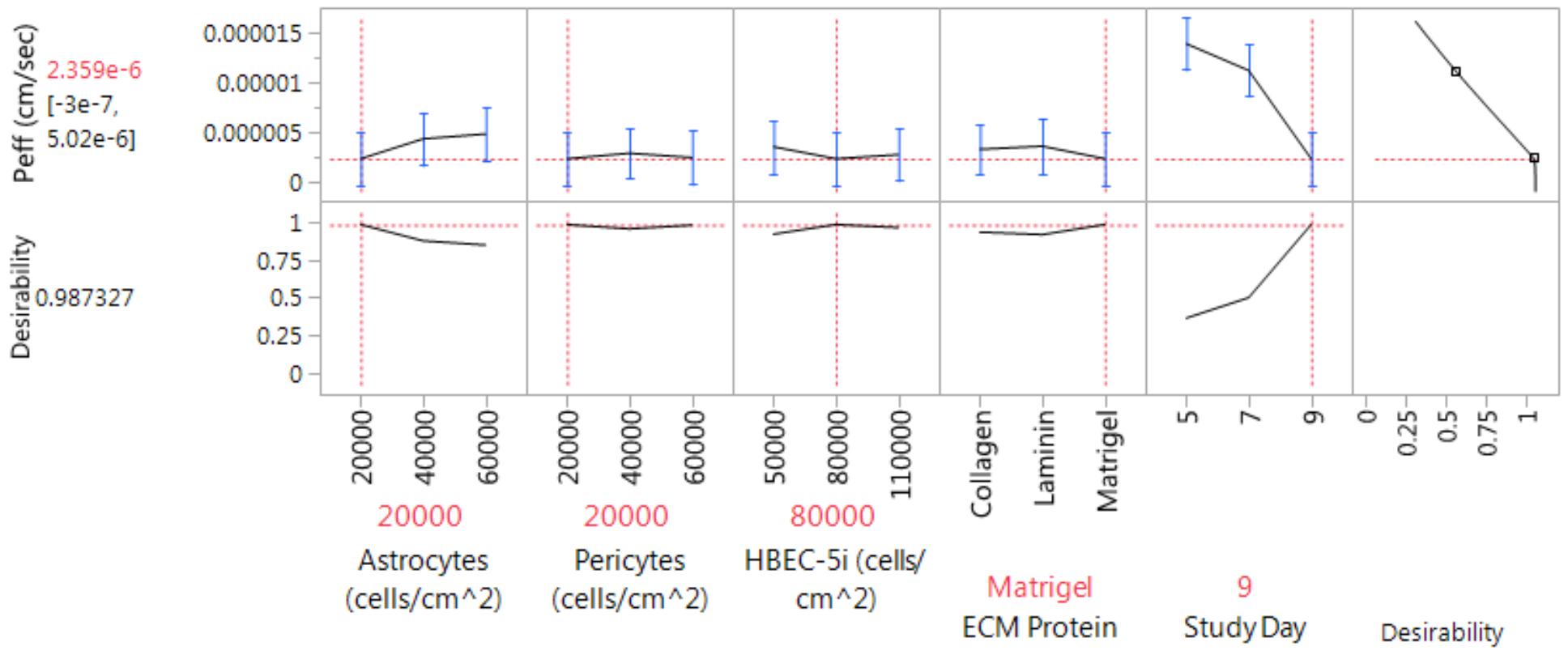

\section{Figure 4}

JMP 13.2 Prediction Profiler generated based on maximizing desirability for Peff based on DOEP. Optimal plating conditions 20,000 cells/cm2 astrocytes and pericytes, 80,000 cells/cm2 HBEC-5i, Matrigel, and 9 
days of endothelial growth. Predicted Peff of $2.4 \times 10-6 \mathrm{~cm} / \mathrm{sec}$ for optimal conditions.

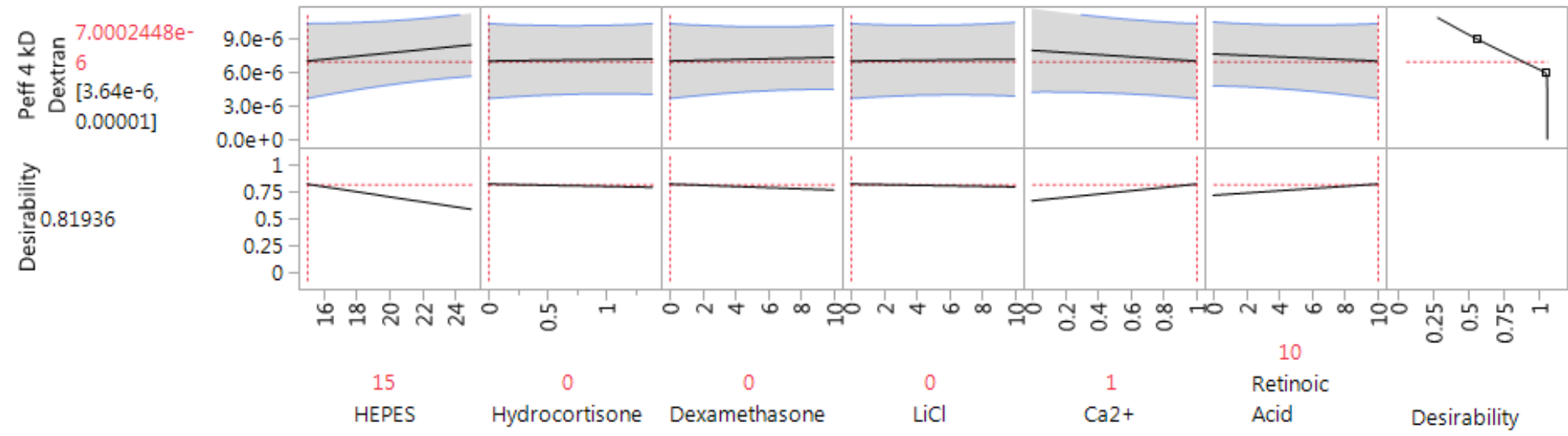

\section{Figure 5}

JMP 13.2 Prediction Profiler generated based on maximizing desirability for Peff of DOEM1. Optimal medium conditions $15 \mathrm{mM}$ HEPES, $1 \mathrm{mM} \mathrm{Ca} 2+$, and $10 \mu \mathrm{M}$ retinoic acid at 9 days of endothelial growth. Predicted Peff of $7.0 \times 10-6 \mathrm{~cm} / \mathrm{sec}$ for optimal conditions.

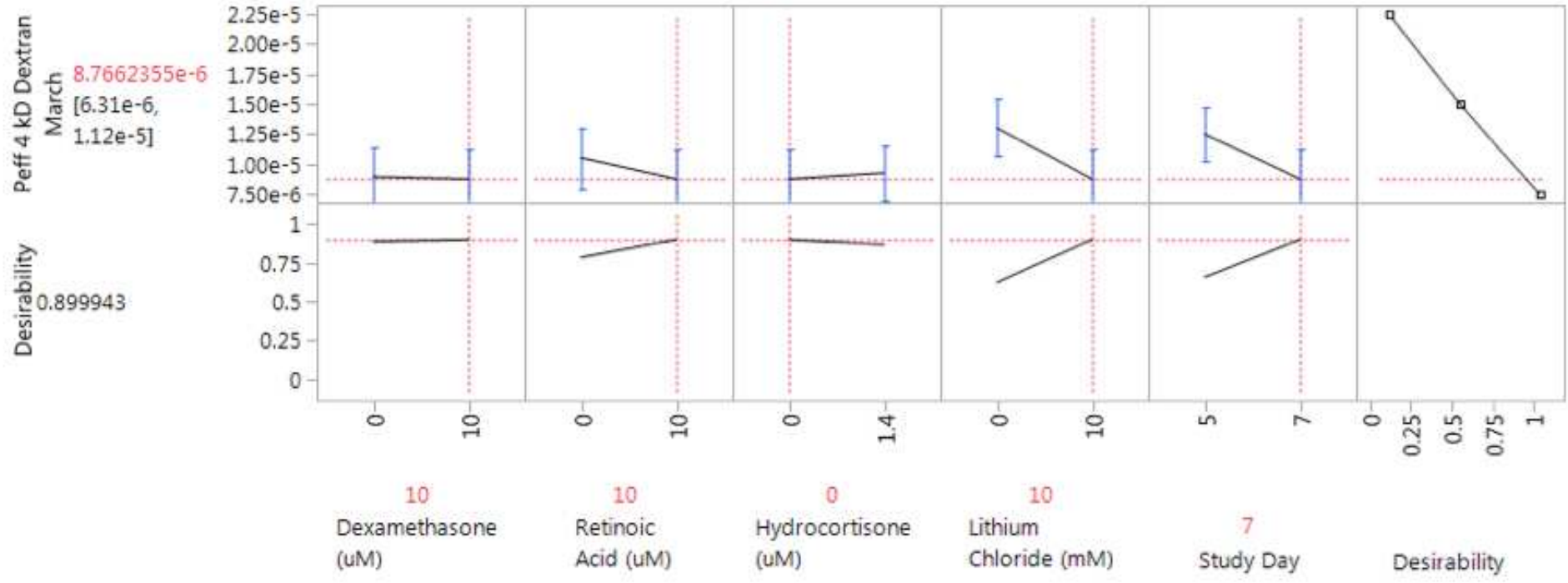

\section{Figure 6}

JMP 13.2 Prediction Profiler generated based on maximizing desirability for Peff of DOEM2. Optimal medium conditions $10 \mu \mathrm{M}$ dexamethasone, $10 \mu \mathrm{M}$ retinoic acid, $10 \mathrm{mM} \mathrm{LiCl}$, through 7 days of endothelial culture. Predicted Peff of 8.8 × 10-6 cm/sec for optimal conditions. 

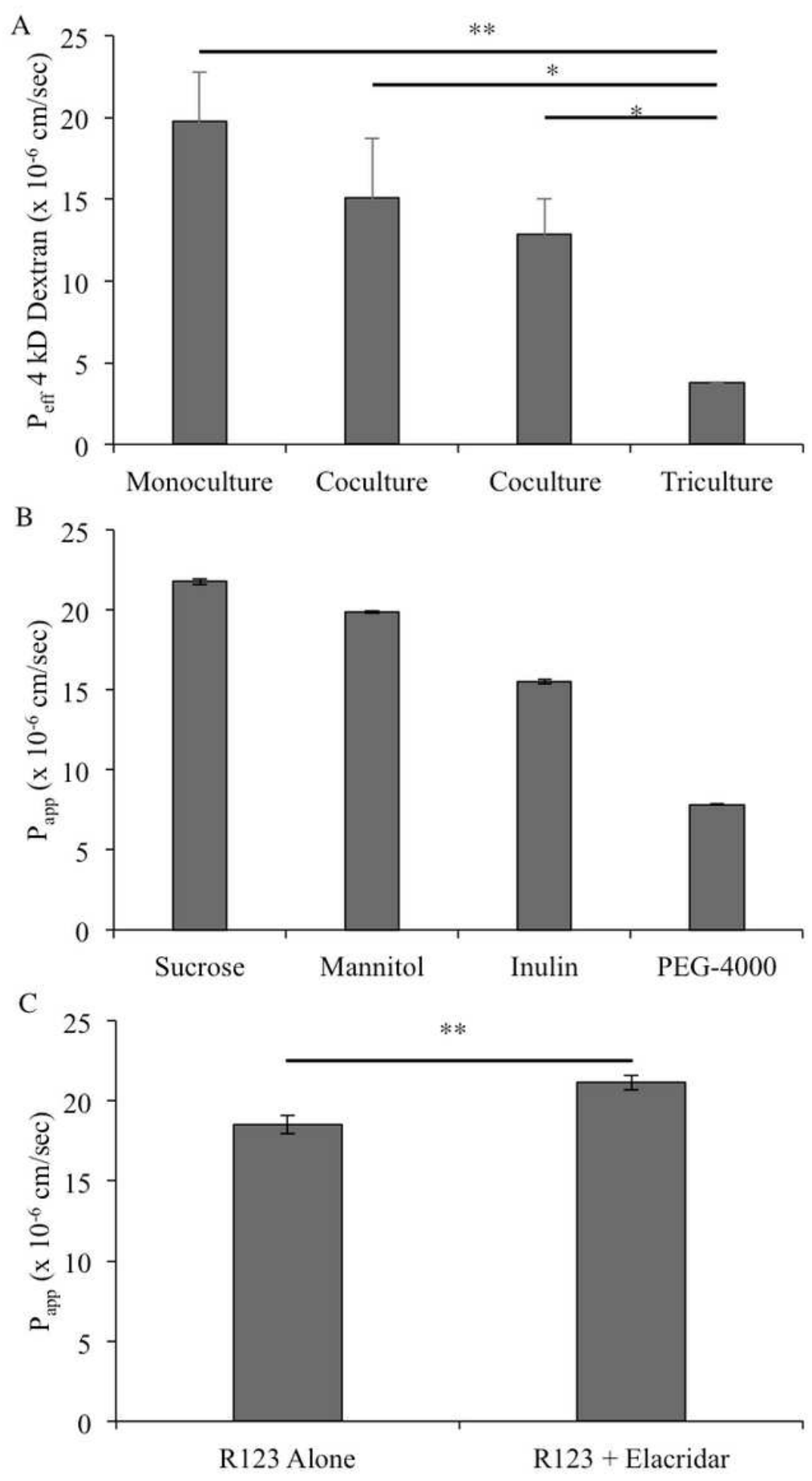

\section{Figure 7}

Optimized Triculture Permeability. (A) Effective permeability (Peff) of 4 kD FITC-dextran across an HBEC5i monoculture, pericyte-HBEC-5i direct contact coculture, astrocyte-HBEC-5i direct contact coculture, and optimized direct contact triculture. Statistical analysis was performed with one-way ANOVA and TukeyKramer post-hoc test. Error bars represent one standard deviation $(n=3) .{ }^{*}, p<0.05$ and $* *, p<0.01$. (B) Apparent permeability of radiolabeled paracellular markers [14C]-sucrose. [14C]-mannitol, [14C]-inulin, 
and [14C]-PEG-4000 across the optimized direct contact triculture. Error bars represent one standard deviation ( $n=3)$. (C) Apparent permeability of P-gp substrate rhodamine 123 (R123) in the presence and absence of P-gp inhibitor elacridar across the optimized direct contact triculture. Assays were run in triplicate and subjected to Student's t-test. Significant difference is indicated by *, p $<0.05$ and **, $p<$ 0.01. Error bars represent one standard deviation $(n=3)$.

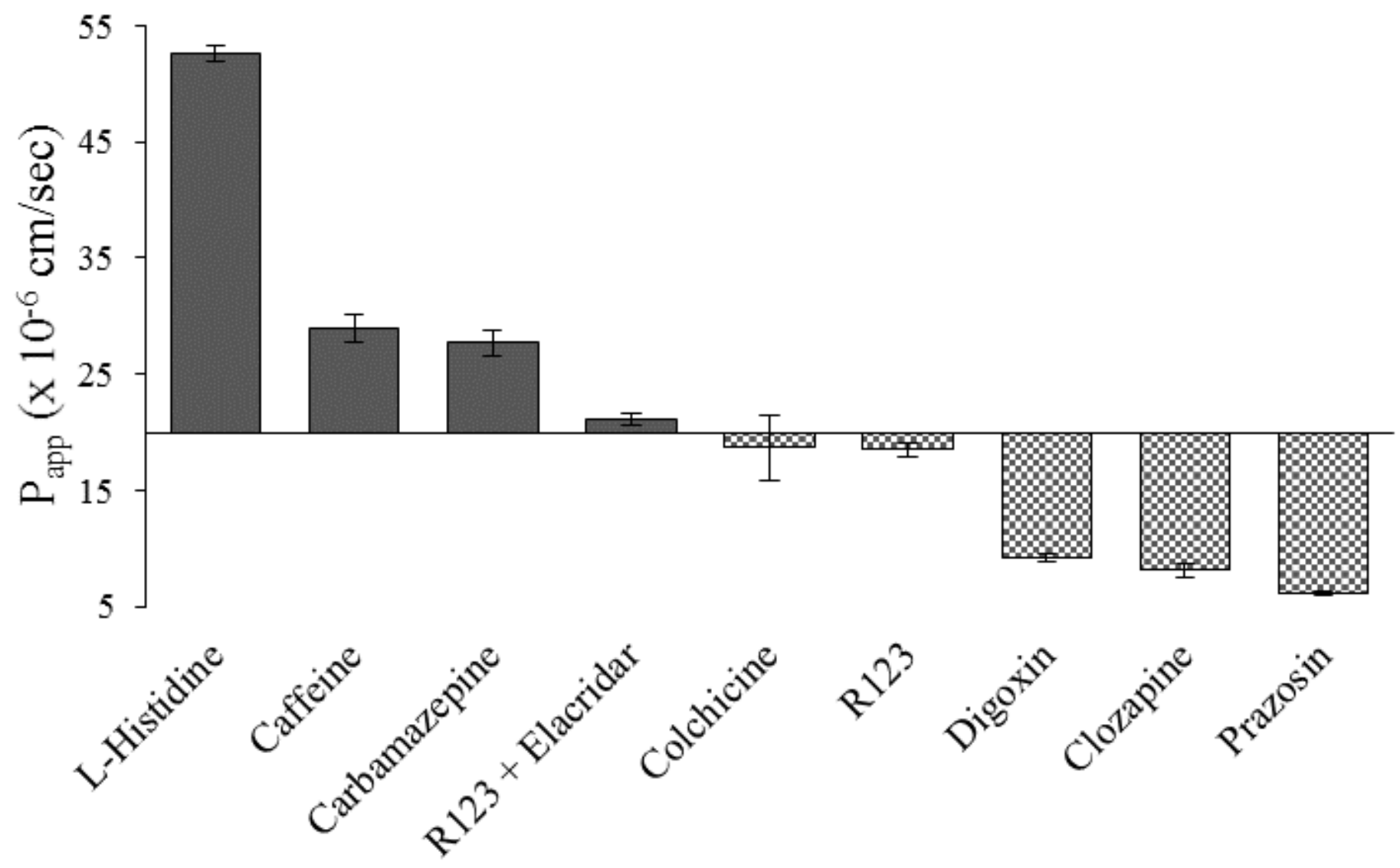

\section{Figure 8}

Apparent permeability of BBB positive (L-histidine, carbamazepine, and rhodamine 123 in the presence of P-gp inhibitor elacridar) and negative (colchicine, rhodamine 123, digoxin, clozapine, and prazosin) permeants across the optimized direct contact triculture. Assays were performed in triplicate. Error bars represent one standard deviation $(n=3)$.

\section{Supplementary Files}

This is a list of supplementary files associated with this preprint. Click to download.

- AdditionalFile1.xlsx

- AdditionalFile2.xlsx

- AdditionalFile3.xIsx 